
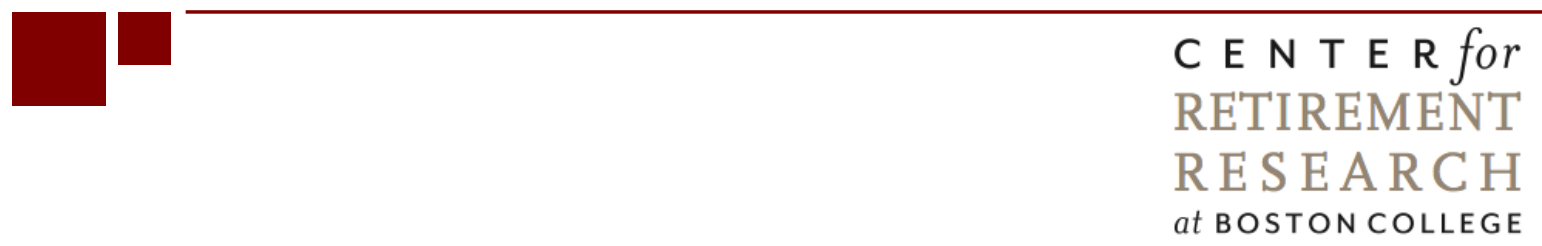

\title{
FINANCIAL SECURITY AT OLDER AGES
}

\author{
Barbara A. Butrica and Stipica Mudrazija
}

CRR WP 2020-19

December 2020
Center for Retirement Research at Boston College
Hovey House
140 Commonwealth Avenue
Chestnut Hill, MA 02467

Tel: 617-552-1762 Fax: 617-552-0191

https://crr.bc.edu

Both authors are with the Urban Institute. Barbara A. Butrica is a senior fellow and Stipica Mudrazija is a senior research associate. The research reported herein was derived in whole or in part from research activities performed pursuant to a grant from the U.S. Social Security Administration (SSA) funded as part of the Retirement and Disability Research Consortium. The opinions and conclusions expressed are solely those of the authors and do not represent the opinions or policy of SSA, any agency of the federal government, the Urban Institute, or Boston College. Neither the United States Government nor any agency thereof, nor any of their employees, make any warranty, express or implied, or assumes any legal liability or responsibility for the accuracy, completeness, or usefulness of the contents of this report. Reference herein to any specific commercial product, process or service by trade name, trademark, manufacturer, or otherwise does not necessarily constitute or imply endorsement, recommendation or favoring by the United States Government or any agency thereof.

(C) 2020, Barbara A. Butrica and Stipica Mudrazija. All rights reserved. Short sections of text, not to exceed two paragraphs, may be quoted without explicit permission provided that full credit, including (C) notice, is given to the source. 


\begin{abstract}
About the Center for Retirement Research
The Center for Retirement Research at Boston College, part of a consortium that includes parallel centers at the National Bureau of Economic Research, the University of Michigan, and the University of Wisconsin-Madison, was established in 1998 through a grant from the U.S. Social Security Administration. The Center's mission is to produce first-class research and forge a strong link between the academic community and decision-makers in the public and private sectors around an issue of critical importance to the nation's future. To achieve this mission, the Center conducts a wide variety of research projects, transmits new findings to a broad audience, trains new scholars, and broadens access to valuable data sources.
\end{abstract}

Center for Retirement Research at Boston College

Hovey House

140 Commonwealth Ave

Chestnut Hill, MA 02467

Tel: 617-552-1762 Fax: 617-552-0191

https://crr.bc.edu

Affiliated Institutions:

The Brookings Institution

Mathematica - Center for Studying Disability Policy

Syracuse University

Urban Institute 


\begin{abstract}
This paper uses financial data from a major credit bureau for a nationally representative 2 percent random sample from more than 250 million consumer records to examine the financial health and indebtedness of older adults. The data cover the years 2010 through 2019 and follow the same consumers over time. Consumer records include numerous sources of debt and information on their total credit available, total balances, amounts past due, debt in collections, and bankruptcies and foreclosures. They also include a nationally recognized credit score that is becoming increasingly utilized by creditors. We supplement these data with the zip-code level information from the American Community Survey on neighborhood characteristics, including racial and ethnic composition, median household income, homeownership, median housing prices, housing cost burdens, and unemployment rates.
\end{abstract}

The paper found that:

- Consumers ages 50 and older are decreasingly indebted since the Great Recession.

- This trend masks the increase in indebtedness among adults ages 70 and older due primarily to mortgages. Not only are they more indebted, but our findings suggest that their financial health - reflected by their credit scores and capacity to borrow - has worsened over time.

- Where older people live matters for their use of debt. Older adults from socioeconomically disadvantaged areas carry debt well into their retirement years, whereas those who live in wealthier zip codes appear to deleverage as they age.

- More than other sources of debt, credit card debt is the most highly correlated with spells of poor credit - increasing both the likelihood of experiencing a spell and reducing the likelihood of exiting a spell. This has negative implications for consumers ages 70 and older since credit cards are their largest source of non-mortgage debt. 


\section{Introduction}

Recent studies have documented the rise in debt among older Americans (Butrica and Karamcheva, 2018; Butrica and Karamcheva, 2013; Butrica and Mudrazija, 2016; Government Accountability Office, 2014; Joint Center for Housing Studies of Harvard University, 2014; Karamcheva, 2013; Lusardi, Mitchell, and Oggero, 2018; Masnick, Di, and Belsky, 2006; Munnell, Hou, and Webb, 2016; Smith et al., 2010). Not only are older adults ever more likely to carry debt, but their level of indebtedness has increased dramatically over time. The reasons behind this trend are numerous and include, among others, policies encouraging homeownership, the proliferation of credit cards, and an explosion in the costs of medical care and higher education. Accordingly, most types of debt have increased over time (Lusardi, Mitchell, and Oggero, 2020).

Mortgages continue to be the largest source of debt among indebted older adults (Joint Center for Housing Studies of Harvard University, 2014). Indeed, the current generation of older Americans is both more likely to have outstanding mortgages (Butrica and Karamcheva, 2013; Butrica and Mudrazija, 2016) and to have taken out larger mortgage loans that they have been repaying over a longer period of time than previous generations (Smith et al., 2010). Increasingly, the norm of repaying mortgages prior to retirement is shifting toward refinancing (Masnick, Di, and Belsky, 2006) as housing prices have increased and people can afford smaller down payments as a share of a property's value (Lusardi, Mitchell, and Oggero, 2020).

While much of the increase in older Americans' debt can be attributed to home mortgages (Moulton, Haurin, and Loibl, 2019), many non-collateralized types of debt have also grown substantially, including credit card debt (Butrica and Karamcheva, 2018), medical debt (Lusardi, Mitchell, and Oggero, 2020), and student debt (Federal Reserve Bank of New York, 2019). As of 2020, for example, adults ages 50 and older held 22 percent of over $\$ 1.5$ trillion in student loans - representing 7 percent of total debt for adults ages 50-59, 4 percent of total debt for those ages 60-69, and 2 percent of total debt for those ages 70 and older (Federal Reserve Bank of New York, 2020).

Although debt is not necessarily concerning and, if used judiciously, can improve financial well-being, excessive debt can have deleterious effects. This is particularly true at older ages when substantial debt burdens can make retirees less financially resilient to various shocks common at those ages, such as a catastrophic health event or the death of a spouse. 
Research suggests that while the financial position of working age people is positively related to debt, the opposite is true for older adults (Pew Charitable Trusts, 2015). Unfortunately, studies find that older Americans have become more leveraged over time (Butrica and Karamcheva, 2018; Butrica and Mudrazija, 2016; Lusardi, Mitchell, and Oggero, 2018). Also, findings suggest that consumer debt overall may be weakly negatively related to intergenerational income mobility, (Brown and Mazewski, 2016) implying that for most people the negative consequences of debt may outweigh the positive ones. This is not necessarily surprising given the general lack of financial literacy, lack of relevant information, and behavioral biases among older adults that contribute to higher debt later in life (Lusardi, Mitchell, and Oggero, 2020).

Heavier debt burdens are likely to result in more hardship for future retirees compared with current retirees (Brown, Dynan, and Figinski, 2019). However, this will not impact all older adults uniformly. In particular, a recent analysis suggests that the overall increase in debt among older Americans likely conceals a critical bifurcation: while the most affluent older adults appear to be using credit to invest in real estate without increasing their debt-to-assets ratio, middle- and lower-wealth older adults have experienced a substantial increase in debt relative to assets (Brown, Dynan, and Figinski, 2019). Among the least affluent older adults, this trend can be largely attributed to an explosion in student debt (ibid). Moreover, more outstanding mortgage debt increases the potential vulnerability of older adults to interest rate hikes (Lusardi, Mitchell, and Oggero, 2018). And although the gender gap in financial hardship at older ages may be narrowing, this is likely due to the deteriorating position of men rather than an improvement among women (Brown, Dynan, and Figinski, 2019).

These trends suggest that less well-off older adults today are increasingly vulnerable to both personal financial and economic shocks: while about one third of the pre-boomer generation reports to struggle financially following a shock, the same is true of over half of the baby boomers (Pew Charitable Trusts, 2015). Consequently, older adults are increasingly likely to default on their debt and fall into bankruptcy (Thorne et al., 2018). Although personal bankruptcy can help highly indebted persons restore their financial health (Dobbie and Song, 2015; Dobbie, Goldsmith-Pinkham, and Yang, 2017), its increasing frequency points to a growing financial strain and vulnerability facing older adults.

Another way in which debt may impact older adults' well-being is by affecting their retirement timing. Indebted persons are more likely to delay retirement (Mann, 2011) and the 
level and type of debt may play a role (Butrica and Karamcheva, 2013; Butrica and Karamcheva, 2018). Consequently, increasing debt over time has contributed more to working longer today than in the past (Lusardi and Mitchell, 2016). However, to the extent that poorer persons may find it more difficult to delay retirement, either because the type of work they do is harder to perform at older ages or because they are more likely to suffer from health limitations than better off older adults, this "solution" could be selective and magnify socioeconomic disparities.

In fact, evidence increasingly suggests that debt and related financial strains may have direct negative effects on health. In particular, studies tie financial strain and indebtedness to poorer mental health outcomes, such as depression and other common mental disorders (Drentea and Reynolds, 2012; Fitch et al., 2011; Meltzer et al., 2012), and with elevated stress levels and hypertension (Leung and Lau, 2017; Sweet et al., 2013). The inability to meet loan payments is associated with a range of negative health outcomes, including a higher prevalence of suicidal ideation and depression, and poorer subjective health and health-related behaviors (Turunen and Hiilamo, 2014).

Given this context, reducing debt and boosting private retirement savings could make future retirees less reliant on Social Security benefits. Conversely, being highly indebted at older ages may exacerbate the impact of various shocks, such as those related to health events, and undermine the adequacy of Social Security benefits to provide sufficient financial support to older adults. Finally, as the ongoing COVID-19 pandemic may alter the patterns of indebtedness, such as lead to an increase in credit card debt as a consumption smoothing strategy among those who lost their jobs and, conversely, encourage deleveraging in the face of continued uncertainty for those who still work and are risk averse (e.g., Collinson, Rowey, and Cho, 2020), it is increasingly important to improve our understanding of the links of different types of debt and financial security at older ages.

In this context, this study examines how financial security changes as people near retirement and the factors associated with changes in financial security. We start by examining changes in total debt and various types of debt over the last decade. We find a modest decline in overall debt among older adults, except for those in their 70s and 80s who are increasingly indebted primarily due to mortgages. Next, we account for the zip code characteristics of consumers and establish that those who live in socioeconomically disadvantaged areas have different patterns of debt and repayment than their peers who reside in wealthier areas. Among 
older consumers, the most leveraged are the youngest in wealthier areas and the oldest in disadvantaged areas. This may suggest that older adults who struggle financially are less able to repay debt as they age and, in fact, may even rely on it to support their standard of living in retirement, whereas their wealthier peers use debt primarily to acquire property and build wealth, largely repaying it by the time they retire or shortly thereafter. Finally, we examine multiple measures of financial health for older adults and their association with different types of debt. Results suggest that using different measures of financial health leads to different conclusions about how the financial health of older adults has changed over time, highlighting the importance of not relying on any single measure of financial health. Some types of debt such as credit card debt and medical collections seem to be particularly detrimental for the financial health of older adults.

\section{Previous Literature}

\section{Trends in Debt}

As of the first half of 2020, total household debt in the United States stood at $\$ 14.3$ trillion, of which mortgages were $\$ 9.8$ trillion (Federal Reserve Bank of New York, 2020). While this is a record high amount, household debt relative to disposable income has been declining since the Great Recession; nonetheless, total household debt equals 99 percent of disposable income today-nearly twice as high as in the late 1950s (Peter G. Peterson Foundation, 2020). Beside mortgages that account for 69 percent of total household debt, other major categories include student debt (11 percent), auto loans ( 9 percent), and credit card debt (6 percent) (Federal Reserve Bank of New York, 2020). Over the past two decades, the main compositional change in household debt has been the rise of student debt, whose share in total debt in the early and mid-2000s was in the low single digits, yet now is second only to mortgages.

Focusing on adults ages 65 and older, the share carrying any debt has increased substantially over the past three decades. While in the late 1980s, just over one-third of elderly households held any debt (37.8 percent in 1989), by 2016 their share surpassed 61 percent (Li, 2019). Simultaneously, the median amount of debt among indebted households more than quadrupled (from less than $\$ 7,500$ to over $\$ 31,000$ ) while the average amount almost tripled (from almost $\$ 30,000$ to close to $\$ 87,000$ ) ( $\mathrm{Li}, 2019$ ). Compositionally, residential debt, both for 
the primary residence and otherwise, remains the dominant component of debt among older adults, largely driving the observed increase in their level of indebtedness, although all components of debt have been on the rise. In fact, the pivot in mortgage lending from younger toward older adults largely accounts for almost 60 percent of the increase in debt held by Americans ages 50-80 with the simultaneous moderate decline among adults under the age of 40 between 2003 and 2015 (Brown et al., 2019).

Another way of looking at debt, however, is to consider the extent to which it may burden older adults given their financial resources - income and assets. On one hand, debt-to-income and debt-to-assets ratios increased at a much more moderate pace than debt alone as incomes and assets of older adults grew. Between 1989 and 2016, the debt-to-income ratio increased from 8.7 percent to 12.4 percent, while debt-to-assets ratio increased from 5.1 percent to 9 percent among households headed by persons ages 65 or older (Li, 2019). Given that loan payment delinquency has roughly remained constant over the same period, this increase seems sustainable for older adults. On the other hand, each successive cohort has become more leveraged. For example, using Health and Retirement Study (HRS) data, Fichtner (2019) finds the median debt-to-assets ratio at age 56-61 for the original survey cohort (individuals born 1931-1941) to be as low as 4 percent, but steadily rising for all subsequent cohorts, and reaching 23 percent for mid- and late baby boomers. Focusing on adults ages 50-64, Ebrahimi (2020) finds their debt-to-net-wealth ratio increased from 16 percent in 1992 to 27 percent in 2016. This seems consistent with the fact that 43 percent of near retirees (persons ages 51-61) report that they feel over-indebted (de Bassa Scheresberg and Lusardi, 2014), and bankruptcies among older adults have been increasing at a pace that is substantially faster than for middle-aged and younger adults, even after adjusting for population aging (Li 2019; Thorne et al., 2018).

While people tend to reduce debt as they age (Fichtner 2019), debt holdings in the United States have increased in recent decades despite the aging of the population. This suggests that either cohort or period effects (or both) dominate the expected age effect that would suggest deleveraging as the population becomes older. According to the available empirical evidence, successive generations of Americans over the age of 50 have been more likely to carry debt and more indebted than their predecessors (Fichtner, 2019). The observed increase in indebtedness is not limited to retirement-age and near-retirement-age populations (Brown, Dynan, and Figinski, 2019; Li 2019), but is also observed for younger adults such as those belonging to Generation $\mathrm{X}$ 
and Millennials, 89 percent and 86 percent of whom, respectively, hold debt (Pew Charitable Trusts, 2015; Collinson, Rowey, and Cho, 2020). This suggests that cohort effects are an important driver of the overall trend of the increase in debt in the United States in recent decades.

Although evidence suggests that younger adults are less debt averse than older adults (e.g., Almenberg et al., 2018), which is consistent with the observed cohort differences in debt trends, empirical findings also support the importance of period effects. Despite the long-term trend of increasing debt, following the Great Recession the overall debt level declined for five years before rising again (Federal Reserve Bank of New York, 2020). Moreover, because they were in their prime homebuying years during the real estate price boom prior to the Great Recession, Generation X members ended up with much more housing debt (and debt overall) than any other generation, including Millennials (Pew Charitable Trusts, 2015). In fact, households headed by adults younger than 35 decreased their debt holdings much more so than other households following the recession, with student debt being the only category of debt to increase in prevalence (Fry, 2013). These findings suggest that changing circumstances are likely the main driver of debt, and for a long time prompted rapid increases in debt by increasing both the demand for loans due to the rising price of education, healthcare, and, in many places, real estate and the supply of debt as financial institutions facilitated access to credit, including secured debt such as mortgages and unsecured debt such as credit cards.

Alongside other residential loans, mortgages account for over 71 percent of total household debt in the United States (Federal Reserve Bank of New York, 2020). Among households headed by older adults, the relative importance of residential loans is even larger since as of 2016 they accounted for full 80 percent of all debt (Li, 2019). For this reason, changes to property prices, the availability of mortgages, mortgage interest rates, tax treatment of mortgages, or any other change that affects residential property markets is likely to have a major impact on trends in overall debt. The long-term trend of this market has been property price increases that have outpaced increases in the incomes of Americans during their prime homebuying years, resulting in successive generations of people holding more housing debt for longer periods. Baby boomers, for example, have more debt than preceding cohorts of older Americans due primarily to the more expensive homes they bought with smaller down payments (Lusardi and Mitchell, 2013). With continued increases in housing prices relative to income, adults born in 1980s who are currently in their prime homebuying years are both less likely to 
own a home by age 30 and face a higher mortgage burden than even the youngest of the baby boomers born in 1960s (Stanford Center on Longevity, 2018).

Over the past decade, student loans have emerged as the largest type of unsecured debt (Federal Reserve Bank of New York, 2020). Although relatively fewer older adults hold student debt (2.4 percent as of 2016), it is the fastest increasing source of their debt with five times as many households ages 65 and older reporting student loans in 2016 compared to 1989 (Li, 2019). The value of student debt held by older adults is increasing at an even faster clip. For example, in just eight years between 2005 and 2013, federal student loans held by borrowers ages 65 and over increased 6.5 times, from $\$ 2.8$ billion to $\$ 18.2$ billion (Government Accountability Office, 2014). Other estimates put the total value of student debt held by persons ages 60 and older at \$67 billion as of 2015 (Consumer Financial Protection Bureau, 2017). Interestingly, much of this debt is not related to older adults' financing their own education, but rather their children's or grandchildren's education, either directly as primary borrowers or co-signers on loans with students as primary borrowers (Consumer Financial Protection Bureau, 2017).

Despite the increase in student debt, credit card debt continues to be the most significant type of unsecured debt among older adults. As of 2016, more than one third of elderly households report having credit card debt with an average balance of $\$ 2,400$, a substantial increase since 1989 when only one fifth of elderly households had any credit card debt with an average balance of $\$ 952$ (Li, 2019). Other types of unsecured debt, such as medical debt and payday loans, may not be as prevalent, but they may have negative impact on the well-being of older adults who incur them as they are commonly unplanned for. In a survey of Americans from various generations, 11 percent of those born between 1928 and 1945 and 21 percent of those born between 1946 and 1964 reported having medical debt, and median amounts were $\$ 500$ and \$1,200, respectively (Pew Charitable Trusts, 2015). Medical debt may be even higher, though, if we expand its definition, as one in six chronically ill adults who take prescription drugs report that their debt is higher due to high prices of these drugs (Heisler, Wagner, and Piette, 2005). Among adults ages 51-61, 20 percent reported using payday loans or pawnshops within the five years preceding the survey (de Bassa Scheresberg and Lusardi, 2014). 


\section{Implications of Debt for Well-being}

Debt at older ages is often perceived negatively because of its possible adverse impact on the retirement security and well-being of older adults. Therefore, it is important to understand whether and to what extent the available empirical evidence supports this notion. Focusing on financial well-being, some research suggests that debt is generally associated with elevated financial risk and lower retirement security (Pew Charitable Trusts, 2015; Lusardi, Mitchell, and Oggero, 2018). One channel through which this may happen is leakage from 401(k) plans as more than a third of persons who take loans from their plans cite debt repayment as the reason (Stark, 2018). However, when focusing on the key metrics of financial vulnerability at older ages, the picture that emerges is mixed. On the one hand, there is little evidence that debt-toincome and debt-to-assets ratios of the current retirees are unsustainable ( $\mathrm{Li}, 2019)$. On the other hand, the trend in these metrics is decidedly more negative as each successive cohort of retirees is experiencing substantial increases in their debt load relative to their incomes and assets (Fichtner, 2019; Lusardi, Mitchell, and Oggero, 2020). Another metric of financial well-being of older adults, bankruptcies, also suggests that the level of their financial distress is increasing at a fast rate (Thorne et al., 2018).

One consequence of increased debt and worsening prospects of achieving retirement security may be delaying retirement. The available evidence strongly supports this notion (Butrica and Karamcheva, 2018; Butrica and Karamcheva 2013; Mann, 2011). Indeed, increasing debt may have contributed to women working longer today than in the past (Lusardi and Mitchell, 2016). While this strategy may offset some of the negative impacts of high debt burdens on retirement security, this strategy may not be universally available to all older adults and, in fact, some of the most vulnerable older adults may not be in the position to extend their careers because of their poorer health or their occupations.

In addition to its impact on financial security, research increasingly suggests that debt and related financial strain may have direct negative effects on health. In particular, studies tie financial strain and indebtedness to poorer mental health outcomes, such as depression and other common mental disorders (Drentea and Reynolds, 2012; Fitch et al., 2011; Meltzer et al., 2012; Selenko and Batinic, 2011; Song et al., 2020), and with elevated stress levels and hypertension (Drentea and Raynolds, 2015; Hamilton et al., 2019; Leung and Lau, 2017; Song et al., 2020; Sweet et al., 2013). The inability to make loan payments on time is associated with a range of 
negative health outcomes, including a higher prevalence of suicidal ideation and depression, and poorer subjective health and health-related behaviors (Turunen and Hiilamo, 2014).

Beyond health and financial well-being, the research also finds that debt impacts negatively life satisfaction more generally (Greenberg and Mogilner, 2020; Kim and Chatterjee, 2019). In a study of college graduates, debt and income accounted for between 40 and 60 percent of the predicted variance of life satisfaction (Tay et al., 2017).

However, the implications of debt on well-being may differ according to the characteristics of debt. Therefore, it is important to review the available empirical evidence about the nature of these links. With respect to the level of debt, studies suggest that both financial well-being (e.g., Brown, Dynan, and Figinski, 2019) and physical and mental health (e.g., Sweet et al., 2013) are negatively impacted by high burden of debt. The amount of unsecured debt in particular has been linked with depression and subjective well-being (Hojman, Miranda, and Ruiz-Tagle, 2016; Zurlo, Yoon, and Kim, 2014), but the symptoms decrease as debt levels decline (Hojman, Miranda, and Ruiz-Tagle, 2016). One study, for example, found no negative impact on subjective well-being once credit card balances dropped below \$2,500 (Bell et al., 2014).

However, one recent study suggests that the type of debt is more important than the amount of debt, at least when it comes to the level of subjective well-being and life satisfaction (Greenberg and Mogilner, 2020). Some findings suggest that the type of debt may even be related with retirement timing (Butrica and Karamcheva, 2018; Butrica and Karamcheva, 2013). Many studies suggest a clear distinction between the impact of secured and unsecured debt on well-being, with the latter exerting a decidedly more negative impact on well-being (Hojman, Miranda, and Ruiz-Tagle, 2016; Lusardi, Mitchell, and Oggero, 2018; Zurlo, Yoon, and Kim, 2014).

Focusing on the individual types of debt, the relationship of housing debt and retirement security is complex. Given that more well-off workers qualify for prime mortgage loans, they are able to build more wealth by the time they reach retirement than they would otherwise, whereas less well-off enjoy no such wealth-building benefit so that buying a home with an expensive mortgage loan that they are unable to repay by the time they retire may exacerbate their financial vulnerability in old age (Pew Charitable Trusts, 2015). Also, although holding a mortgage in retirement seems to be correlated with a lower level of financial satisfaction, once 
financial capability and beliefs are controlled for, this relationship disappears (Seay et al., 2015). Mortgages also show no relationship with subjective well-being (Brown, Taylor, and Wheatley Price, 2005).

The relationship is clearly negative for some other types of debt, such as student loans and credit card debt, among others. Carrying student debt in retirement can have a substantial negative impact on the financial well-being of retirees. Student loans have been found to have a negative impact on retirement savings (Elliott, Grinstein-Weiss, and Nam, 2013) and on capital accumulation more generally (Elliott, Grinstein-Weiss, and Nam, 2013b). Other research suggests that the negative impact of student debt may manifest itself primarily through reduced consumption and an increase in credit card or other types of debt rather than lower retirement savings (Rutledge, Sanzenbacher, and Vitagliano, 2016). An estimate by Munnell, Hou, and Webb (2016) suggests that if working-age households held as much student debt as recent college graduates, an additional 4.6 percent of households would be at risk of inadequate income in retirement. The reason why student debt may hurt financial well-being in retirement more than some other sources of debt is that it generally cannot be discharged in bankruptcy and can lead to reductions in federal payment such as Social Security benefits (Government Accountability Office, 2014). Student debt has also been found to be negatively related to health, including self-rated health and psychological problems (Kim and Chatterjee, 2019), as well as life satisfaction (Greenberg and Mogilner, 2020) and subjective well-being (Archuleta, Dale, and Spann, 2013; West, Shanafelt, and Kolars, 2011).

For credit card debt, arguably more worrisome than the amount of debt is whether or not credit cards are used expensively, that is, whether credit card holders exhibit behaviors consistent with high-interest borrowing, including making only minimum payments, paying late fees, paying over-the-limit fees, or using credit cards for cash advances. A survey of adults ages 5161 suggests that this might be the case, as 39 percent of respondents used credit cards expensively (de Bassa Scheresberg and Lusardi, 2014). In addition to its negative financial impact, credit card debt has been linked to negative impacts on mental health, particularly for persons in the middle of the income distribution (Hodson Dwyer, and Neilson, 2014), and with lower subjective well-being (Bell et al., 2014).

While there is much less research available on other sources of debt, the established pattern of the relationship remains broadly similar: unsecured debt, especially if unexpected or 
expensive, has a negative impact on the well-being of borrowers. For example, medical debts are among the common reasons for emergency withdrawals from 401(k) accounts (Collinson, Rowey, and Cho, 2020), which may adversely impact retirement security. Conversely, research finds that army emergency relief fund borrowing does not adversely impact subjective wellbeing, presumably because these loans bear no interest (Bell et al., 2014).

Beyond the amount and type of debt, the research on possible links of other characteristics of debt with individual well-being is scant. However, elements such as the duration of holding debt, timing of incurring debt, or interactions between different types of debt may also be linked with well-being over the adult life course, including in retirement. Using the credit bureau data on debt, the present study will examine how different characteristics of debt held by older adults vary by age and over time, thereby improving our understanding of the dynamics of debt at older ages and, by extension, providing useful information for future studies of the implications of holding debt at older ages.

\section{Data and Methods}

We use financial data from a major credit bureau for a nationally representative 2 percent random sample from more than 250 million consumer records. The data cover the years 2010 through 2019 and follow the same consumers over time. Consumer records include more than 124 depersonalized variables covering various types of credit —including the number of trade lines (e.g., credit cards, auto loans), total credit available, total balance, amounts past due, debt in collections, and bankruptcies and foreclosures. They also include a nationally recognized credit score that is becoming increasingly utilized by creditors and covers more consumers than traditional scores.

Consumer records also include age, but do not include other demographic information. They also lack information on income and assets. For additional information about consumers and their conditions, we use geographic identifiers to match zip-code level data from the American Community Survey on neighborhood characteristics, including racial and ethnic composition, median household income, homeownership, median housing prices, housing cost burdens, and unemployment rates.

Our analyses focus on adults ages 50 and older and their financial security at different ages. We create several measures of total debt. Our primary measure captures balances on open 
trades plus balances on derogatory trades - those charged off or in collections. Specifically, this measures includes mortgages (first mortgages, second mortgages, and home equity lines of credit), credit cards, auto loans, student loans, other debt (debt not captured in the other categories, including installment loans, personal business loans, and credit loans), and debt in collections. Our collections measure includes both medical and nonmedical collections. However, our data extract does not enable us to distinguish the original source of nonmedical collections (e.g., credit cards versus student loans, etc.). A second measure of debt excludes debt in collections and a third measure of debt represents only non-mortgage debt. All debt values are in 2019 dollars.

These data provide a more accurate description of the debt and financial health of Americans than is conveyed in self-reported data. However, they differ from other commonly reported data sources, such as the Survey of Consumer Finances, in some important ways. First, while our data provides a nationally representative sample of consumers with credit, they naturally exclude those without credit or those who use alternative sources of credit. According to the most recent survey, 6 percent of adults are unbanked because they do not have a checking, savings, or money market account. Among those who are unbanked, around two-fifths use alternative financial services such as check cashing services, payday loans, and paycheck advances. Additionally, 16 percent are underbanked because they have a bank account but use alternative financial services. These services are typically more expensive than mainstream financial services (Board of Governors of the Federal Reserve System, 2019). Second, our data are extracts of the credit bureau data in August of each year. So consumers who typically pay off their balances each month and would self-report that they do not have any balances could appear in our analysis with balances, depending on their payment date and the date of the data extract. Third, our data include individuals rather than households. Thus, spouses who cosign loans will each show up in our analysis with the same total loan balance. The second and third difference, one could argue, overstate both the share of consumers with debt and the value of their debt. We would argue, however, that these data accurately capture debt held by individuals at a point in time. If, for example, someone who regularly pays off his or her credit card balance suddenly loses their job and cannot pay off their balance, our analysis accurately reflects what they owe, whereas self-reported data in other surveys may miss it. Similarly, if someone's spouse dies, they are still responsible for the debt and our analysis reflects what they owe. 
Finally, our measure of debt is more comprehensive than what is captured by most self-reported surveys because we also include other debt on open trades and debt in collections.

In addition to analyzing total debt and its sources, we also analyze financial health using indicators of delinquent payments, debt in collections, bankruptcy, foreclosure, and credit utilization. We also examine credit scores. Credit score ranges vary depending on the model. In our analysis, good credit scores range from 661 to 780 and are considered prime. Near prime credit scores range from 601 to 660, subprime credit scores are below 601, and super prime credit scores are above 780 .

We then estimate fixed-effects linear probability regression models of the likelihood of falling into and exiting spells of poor credit over a 10-year period for those with good credit in 2010. We define good credit as credit scores that are prime or super prime and poor credit as credit scores that are near prime or subprime. We use the following equation:

$$
y_{i t s z}=\beta_{0}+\beta_{1} A g e_{i t s z}+\beta_{2} D E B T_{i t s z}+\beta_{3} O T H E R_{z t}+\lambda_{t}+\gamma_{s}+\varepsilon_{i t s z}
$$

where subscripts $i, t, s$, and $z$ index consumers, years, states, and zip codes, $y_{i t s z}$ indicates whether consumers have poor credit; $A g e_{i t s z}$ captures their age; $D E B T_{i t s z}$ measures the value of debt from different sources, including mortgages, credit cards, auto loans, student loans, other debt, and collections; and $O T H E R_{z t}$ measures the characteristics of consumers' zip codes. The model also includes year and state fixed effects $\left(\lambda_{t}\right.$ and $\left.\gamma_{s}\right)$. The main coefficient of interest is $\beta_{2}$.

\section{Results}

In this section we present our findings. We begin by analyzing changes in total debt and its sources over time. Next, we analyze individual changes in total debt over time and the sources attributed to those changes. We then describe how the previous patterns of debt vary by zip code characteristics. Next, we examine various measures of financial health. Finally, we present regression results for the likelihood of falling into and exiting poor credit and the sources of debt correlated with those likelihoods. 


\section{Changes in Total Debt Over Time}

Among consumers ages 50 and older who use mainstream financial services, around 9 in 10 have debt that includes balances on open trades plus debt in collections. The other 1 in 10 without debt have open trades, which is why they are in the sample, but they have paid off these balances and they do not have debt in collections. ${ }^{1}$ Over time, the share of older adults holding debt changed very little_-declining slightly from 90 to 88.8 percent between 2010 and 2019

(Figure 1). Among those with debt, the median amount declined from $\$ 23,800$ to $\$ 20,300$ between 2010 and 2013, likely reflecting the slow recovery from the Great Recession, and then remained fairly constant through 2019.

The next figures look more carefully at how debt changes at different ages and how this pattern has changed over time. Figure 2 examines the share of older adults with debt. The first panel considers total debt and the second panel focuses on debt excluding collections. Because many older adults are homeowners with outstanding mortgage balances and because mortgage debt comprises the largest share and value of overall debt for most adults, the third panel considers non-mortgage debt — that is debt plus collections, but excluding mortgages. Generally, the proportion of indebted older adults remains fairly high and constant until the ages of 68 to 70 when it begins to decline with age much more steeply. A significant portion of older adults has debt in collections, thus excluding it reduces the share with debt in 2019 by as much as 13 percentage points for the youngest and 8 percentage points for the oldest in our sample. Between 2010 and 2019, the share of indebted adults remained fairly constant for those under age 80, but declined slightly for those ages 80 and older.

Although the share of the oldest-old with debt has declined over time, their indebtedness increased. In contrast, the share of younger-old with debt remained fairly constant over time; however, their indebtedness declined (Figure 3). Between 2010 and 2019, the median value of total debt among those with debt declined for those ages 50 to 68 and increased for those ages 69 and older. The pattern of debt excluding collections is similar. However, the pattern of nonmortgage debt looks very different. At all ages, the median value of non-mortgage debt increased between 2010 and 2019; however, the percentage increase was significantly larger for those ages 68 and older than for their younger counterparts.

\footnotetext{
${ }^{1}$ As mentioned earlier, these data naturally exclude close to 20 percent of adults of all ages who do not use mainstream financial services (Board of Governors of the Federal Reserve System, 2019).
} 


\section{Changes in Sources of Debt Over Time}

Figures 4a through $4 \mathrm{f}$ examine age-related trends in sources of debt and how they have changed between 2010 and 2019. As expected, the share of older adults with mortgage debt declined with age in both years; however, the trend lines cross at age 70 (Figure 4a). Thus, adults ages 50 to 69 are less likely to carry mortgage debt in 2019 than in 2010, and the difference is substantial. For example, 46.6 percent of 50-year olds had mortgages in 2010, compared with only 39.8 percent in 2019 . In contrast, adults ages 70 and older are more likely to have mortgage debt in 2019 than in 2010.

The share of older adults with credit card debt rises somewhat with age until around 75, and then declines dramatically (Figure 4b). Between 2010 and 2019, the percentage of older adults with credit card debt increased slightly for adults ages 50 to 59 and declined slightly for those ages 78 and older. While the prevalence of auto loans (Figure 4c) and student loans (Figure 4d) declines with age, both are significantly more common among older adults in 2019 than in 2010. It is likely that older adults are taking out some of these loans for their children and grandchildren, although we cannot be certain from the data. The share of older adults with other debt (Figure 4e) and debt in collections (Figure 4f) also declines with age; however, the prevalence of these sources of debt has not changed much over time.

Among those with different sources of debt, Figures 5a through $5 \mathrm{f}$ depict the age-related changes in the median value of those sources of debt and how their patterns have changed over time. Not surprising, mortgage debt declines with age as homeowners pay down their loans or downsize (Figure 5a). Between 2010 and 2019, however, there is a noticeable increase in the median value of mortgage debt among adults ages 67 to 85 . Among those with credit card debt, the median value increased between 2010 and 2019 across all ages (Figure 5b). Among those with auto loans, the median value increased over time for adults under age 80, particularly those ages 50 to 59, and declined for those ages 80 to 89 (Figure 5c). Among those with student loans, the median value dramatically increased between 2010 and 2019 for many ages, but particularly for those ages to 50 to 59 (Figure 5d). For example, the median value of student loan debt increased $\$ 6,800$ for 50-year-olds from $\$ 14,300$ in 2010 to $\$ 21,100$ in 2019 . The median value of other debt dramatically increased between 2010 and 2019 across all ages (Figure 5e), while the median value of debt in collections dramatically declined over the same time period (Figure $5 f)$. 
Since the median value of total debt declined between 2010 and 2019, while most of its sources increased over the same period, it is plausible that the overall decline in total debt is attributable primarily to population aging rather than the trend of deleveraging among older adults. In other words, since we do not observe that people carry less debt at any given age, but we know that people tend to have less debt as they age, the fact that the average age of our sample increases over time due to population aging could largely account for less debt that it has in 2019 compared to 2010. Indeed, the only component of debt that appears to decline over time across all ages is debt in collection (since the prevalence remained roughly constant over time, but the median value declined substantially for all ages). In fact, the lifecycle aspect of the decline in debt propelled by population aging seems to be strong enough that it is not offset by the fact that at ages 68 and older the overall median debt is actually higher in 2019 than in 2010, while the prevalence of debt is effectively unchanged.

Table 1 describes the patterns in debt and changes over time for specific age groups. It clearly shows that while the value of total debt and debt plus collections declines with age, adults ages 50 to 69 are less indebted and those ages 70 to 89 are more indebted today than they were in 2010. Still, even in 2019, the youngest old have significantly more debt than the oldest old. In 2019 , median total debt was $\$ 34,700$ for those ages 50 to 59 and $\$ 21,700$ for those ages 60 to 79 , down from $\$ 45,300$ and $\$ 26,100$, respectively, in 2010 . In contrast, it was $\$ 10,800$ for those ages 70 to 79 and $\$ 2,400$ for those ages 80 to 89 , up from $\$ 6,800$ and $\$ 1,500$, respectively, in 2010. Median non-mortgage debt increased between 2010 and 2019 across all ages. In 2019, median non-mortgage debt was $\$ 12,600$ for those ages 50 to $59, \$ 8,100$ for those ages 60 to 69 , $\$ 4,600$ for those ages 70 to 79 , and $\$ 1,700$ for those ages 80 to 89 . Outstanding balances have increased over time across all age groups on mortgages (except for 60-69 year olds), credit cards, auto loans (except for 80-89 year olds), student loans, and other debt. Collections have declined over time for all age groups.

Figure 6 shows the average share each source contributes to total debt by age and year. ${ }^{2}$ As expected, mortgages are the largest source of debt for 50-59 year-olds, followed by credit cards, collections, auto loans, other debt, and student loans. At the other end of the age range, credit cards are the largest source of debt for 80-89 year-olds, followed by mortgages, collections, auto loans, other debt, and student loans. Between 2010 and 2019, adults ages 50 to

\footnotetext{
${ }^{2}$ This differs from the share of average total debt from each source.
} 
69 experienced a relatively large decline in the share of total debt from mortgages. This decline is entirely offset by the combined increase in the share of total debt from auto loans and credit cards. In contrast, those ages 70 to 89 experienced a relatively large decline in the share of total debt from credit cards. This decline was offset by an increase in the share of total debt from auto loans, followed by mortgages. We show a much larger share of total debt from credit cards than some other studies ( $\mathrm{Li}, 2019)$. This could happen if our data include a lot of people who pay off their monthly credit card balances, but whose balances were still positive at the time of the credit bureau data extract. To the extent that this explains our higher share of credit card debt, our analysis still accurately captures the amount of credit card debt owed at the time and which, even if intended, might not be paid off each month.

\section{Individual Changes in Debt Over Time}

Next, we follow individuals from 2010 through 2019 to track changes in their debt and present the findings according to their age in 2010. Nearly a third (31.2 percent) of older adults experienced an increase in their debt between 2010 and 2019- the increases ranged from 32.2 percent of those ages 50 to 59 to 22.4 percent of those ages 80 to 89 (Table 2). The average increase in debt among those experiencing an increase was $\$ 53,600$ - ranging from $\$ 16,500$ for 80-89 year-olds to $\$ 66,100$ for 50-59 year-olds — with the majority of the increase in total debt attributable to an increase in mortgage debt.

Excluding mortgage debt, the average increase in debt was $\$ 15,000$ —ranging from $\$ 5,000$ for $80-89$ year-olds to $\$ 18,100$ for 50-59 year-olds. The biggest driver of the increase in non-mortgage debt is attributable to auto loans. For 50-59 year-olds, 39 percent of their increase was from auto loans, 22 percent from other sources, 20 percent from credit cards, 13 percent from student loans, and 6 percent from debt in collections.

Around two-thirds of older adults, regardless of age, experienced a decline in debt between 2010 and 2019. The average decline in debt among those experiencing a decline was $\$ 86,000$ - ranging from $\$ 30,400$ for 80 -89 year-olds to $\$ 99,200$ for $50-59$ year-olds. Again, the majority of the decline in total debt can be attributed to a reduction in mortgage debt as people pay down, pay off, or downsize their mortgages.

The average decline in non-mortgage debt was $\$ 17,900$ - ranging from $\$ 7,400$ for $80-89$ year-olds to $\$ 20,800$ for $50-59$ year-olds. For adults under age 70 , the biggest driver of declining 
non-mortgage debt was attributable to auto loans. For those ages 70 and older, the decline in debt was driven primarily by a decline in credit card debt.

Focusing on the change in debt between 2010 and 2019 understates the year-to-year variation in debt that some consumers experience. Figure 7 compares the change in the value of debt between 2010 and 2019 (absolute value) with the difference between the highest and lowest values of debt in the same 10-year period. Overall, the median absolute change in debt between 2010 and 2019 is $\$ 24,300$, but the median difference between the highest and lowest values is $\$ 43,500$. Even excluding mortgage debt, the story is similar. The median absolute change between 2010 and 2019 in non-mortgage debt is $\$ 7,300$, but the median difference between the highest and lowest values is more than twice the amount at $\$ 19,900$.

\section{Differences in Debt by Zip Code Characteristics}

\section{Zip Code Level Median Household Income}

We begin by looking at differences in debt by median household income in zip codes. Similar to HUD's methodology for determining program eligibility by comparing individuals' incomes against the Area Median Income (AMI), we define our zip code-level income groups by comparing median household income in one's zip code to median household income in their county. High-income zip codes are those with median household incomes that are at least 120 percent of the county median income and low-income zip codes are those with median household incomes that are 80 percent of the county.

We generally find that median total debt, among those with debt, is highest among older adults in high-income zip codes and lowest among those in low-income zip codes (Figure 8). Differences in median debt by zip code median income are largest for consumers ages 50-59 and those ages 60-69; however, these differences narrow over time. For example, the ratio of debt in high-income zip codes to debt in low-income zip codes was 4.8 in 2010 and 4.4 in 2019 for 5059 year-old residents. In contrast, differences in median debt by zip code median income are significantly smaller for adults ages 70 to 79 , but they increased somewhat over time. For example, the ratio of debt in high-income zip codes to debt in low-income zip codes was 1.1 in 2010 and 1.5 in 2019 for 70-79 year-old residents. Especially interesting is that 80-89 year-old residents in high-income zip codes carry the same amount of debt as their counterparts in lowincome zip codes, and this pattern is evident across the 10 -year observation period. Because the 
largest source of debt for most Americans is their mortgage and because those with low incomes are less likely to be homeowners, we also examined patterns of non-mortgage debt by zip codelevel household income (Figure 9). Generally, we find that the patterns of non-mortgage debt mirror those observed for total debt with two notable differences. The first is that the difference in debt between residents in high- and low-income zip codes is considerably smaller. The second is that this difference has increased slightly over time for all age groups as residents in high-income zip codes have experienced larger increases in debt over time than their counterparts in low-income zip codes. It is important to emphasize that high levels of debt do not necessarily reflect poor financial health. In fact, we find that mean credit scores are significantly higher among residents in high-income zip codes than they are for those in lowincome zip codes (not shown).

Lastly, we analyze differences between residents in high- and low-income zip codes in the sources of their debt in 2019 (Figure 10). For high-income residents, we find that a significantly large share of their debt comes from mortgages, particularly at younger ages, and from credit cards, particularly at older ages. Low-income residents owe a smaller share of their debt to mortgages and credit cards, but a significantly larger share of their debt to collections.

\section{Zip Code Level Percentage of White and Nonwhite Residents}

Next we examine differences in debt by the percentage of white and nonwhite zip code residents. We define a zip code as having a high percentage of nonwhite residents if less than 50 percent of its residents are white non-Hispanic. Figure 11 shows large differences in debt for 5059 year-olds and 60-69 year-olds residing in zip codes with a high percentage of white residents compared with their counterparts who reside in zip codes with a high percentage of nonwhite residents. For 50-59 year-olds, this difference has narrowed over time, but for 60-69 year-olds it has increased somewhat. The pattern is very different for adults ages 70 and older. Among 7079 year-olds, median debt was higher in 2010 for those living in zip codes with a high percentage of nonwhite residents than it was for those living in zip codes with a high percentage of white residents. Between 2010 and 2019, median debt increased significantly more for those living in

predominantly white zip codes than it did for those living in predominantly nonwhite areas. As a result, the trend lines cross each other in 2014 and median debt is slightly higher for 70-79 yearolds living in mostly white zip codes than it is for those living in most nonwhite zip codes. In 
contrast, median debt for 80-89 year-olds is higher for those living in nonwhite zip codes than it is for those living in mostly white zip codes.

A similar story emerges when considering non-mortgage debt. Among adults under age 70, those living in mostly white zip codes carry more debt than those living in mostly nonwhite zip codes (Figure 12). Moreover, the difference between white and nonwhite zip codes has increased over time. Among adults ages 70 and older, in contrast, those residing in mostly white zip codes have less debt than their counterparts in mostly nonwhite areas. Additionally, the difference in debt values between white and nonwhite zip codes has declined over timeparticularly for 70-79 year-olds. Again, we find that mean credit scores are significantly higher among consumers who reside in areas with a high percentage of white residents than they are for those who reside in areas with a high percentage of nonwhite residents (not shown).

Finally, we examine the sources of debt in 2019 and how they differ between residents living in predominantly white versus nonwhite neighborhoods (Figure 13). Except for those ages 80 to 89 , older adults living in mostly white zip codes have a significantly larger share of their debt in mortgages than their counterparts living in mostly nonwhite zip codes. Except for those ages 50 to 59, older adults in predominately white areas also carry a larger share of their debt in credit cards than their counterparts in predominately nonwhite areas. In contrast, residents in mostly nonwhite zip codes have a significantly larger share of their debt in collections than residents in mostly white zip codes.

\section{Financial Health}

It is important to note that the amount of debt older adults carry is not necessarily a problem as long as they can service their debt. The inability to do this is concerning for anyone who assumes debt, but particularly so for older adults. Once they retire and no longer have earnings, can they still afford to make their monthly payments? In addition, as people age they are increasingly likely to experience life changing events, such as a catastrophic health episode (Johnson, Mermin, and Uccello, 2006). Not only might such events make servicing their original debt more difficult, but older adults might take on more debt to get through these periods. For example, borrowing to pay for expensive hospital bills. In this section, we assess the financial health of older adults using different measures. 


\section{Credit Score}

Credit scores generally increase with age until the early 80s when they begin declining (Figure 14a). Not long ago, it was reported that the average FICO credit score hit an all-time high of 706 (Singletary, 2019). In our analysis, we also observe a 20-point increase between 2010 and 2019 in average credit scores over all consumers ages 18 and older; however, the increase is driven entirely by consumers under age 50 (not shown). Figure 14a shows that average credit scores declined between 2010 and 2019 for consumers ages 50 and olderparticularly those ages 75 and older. This pattern is also reflected in the age distribution of subprime scores (Figure 14b). They decline dramatically with age until around age 80 when they flatten out. Moreover, consumers with subprime scores are less prevalent in 2019 among adults ages 50 to 55, but more prevalent among those ages 74 and older. Finally, the share of consumers with super prime credit scores increases with age until around 80 and then declines at the oldest ages (Figure 14c). While the prevalence of super prime scores declined in 2019 across all ages, the decline was particularly pronounced for those over age 80 .

As shown in Figure 15, the majority of adults ages 80 to 89 have super prime credit scores, followed by prime, near prime, and then subprime credit scores. In contrast, adults ages 50 to 59 are most likely to have prime credit scores, followed by super prime, subprime, and near prime credit scores. Between 2010 and 2019, the share of older adults with super prime credit scores declined dramatically, particularly for those ages 80 to 89 . Offsetting this decline, the share of older adults with prime credit scores increased, again most dramatically for the oldest ages. Subprime credit scores are most likely among adults ages 50 to 59, followed by those ages 60 to 69 and those ages 70 to 79 . Adults ages 80 to 89 are least likely to have subprime credit scores. Between 2010 and 2019, the share of older adults with subprime credit scores remained fairly constant. In contrast, the share with super prime scores declined for all age groups, but particularly for those ages 80 and older. Thus, based on credit scores, there is no evidence that older adults have become financially healthier over time. If anything, the evidence suggests that the oldest ages have become less financially healthy. 


\section{Late Payments, Foreclosures, Bankruptcies, and Collections}

Other measures of financial health suggest that older adults were financially healthier in 2019 than they were in 2010. Snapshots of 2010 and 2019 reveal that relatively few older adults have payments past due, delinquent mortgages, foreclosures, or bankruptcies (Figure 16a).

Moreover, the share of older adults experiencing any of these events has declined between 2010 and 2019. While this finding points to an increase in financial health, those ages 70 to 89 , and particularly those ages 80-89, experienced smaller improvements in these measures of financial health over this time period than their younger counterparts. Still, it is important to consider the frequency of these events over longer periods. The share who have ever experienced one of these events between 2010 and 2019 is considerably higher than the incidence in either of these two years (or any other single year). For example, 3.2 percent of older adults had payments past due in 2010 and only 2.1 percent had payments past due in 2019. Between 2010 and 2019, however, 12.8 percent had payments past due. For the most part, financial health improves with age - with 16 percent of adults ages 50 to 59 experiencing late payments at some time between 2010 and 2019 compared with only 6.8 percent of those ages 80 to 89 .

Another measure of financial health is having debt in collections. The proportion of older adults with debt in collections is significantly higher than the other measures of financial health (Figure 16b). Moreover, the share remains fairly high in both 2010 and 2019. In 2019, about a third of adults age 50 to 59 , a quarter of those ages 60 to 69 , and close to a fifth of those ages 70 to 79 and those ages 80 to 89 had debt in collections. Between 2010 and 2019, more than two-fifths of the 50-59 year-olds, a third of 60-69 year-olds, and around a quarter of 70-79 year-olds and 80-89 year-olds ever had debt in collections.

The amount delinquent and in collections declines with age and over time. Overall the median balance on payments past due was $\$ 2,000$ in 2010, but only $\$ 700$ in 2019 (Figure 17a). The median mortgage balance for those with late payments was $\$ 165,100$ in 2010 and $\$ 94,300$ in 2019 (Figure 17b). Likewise, the median amount owed for those with debt in collections declined from \$2,600 in 2010 to only $\$ 1,600$ in 2019 (Figure 17c).

\section{Capacity to Borrow}

The benefits of establishing credit lines and paying bills on time is that it increases people's ability to borrow money relatively quickly when emergencies or other unexpected 
events arise. Next we consider older adults' capacity to borrow by examining their credit utilization - the total debt they carry on open trades relative to their total credit limit. The lower their credit utilization, the greater their capacity to borrow. As expected, older adults are more highly leveraged at the youngest ages, with mortgages and student loans outstanding, than they are at the oldest ages. With higher rates of credit utilization, the youngest old have less capacity to borrow than the oldest old. In 2010, for example, 35.8 percent of 50-59 year-olds, but only 14.6 percent of 70-79 year-olds and 8 percent of 80-89 year-olds had borrowed at least 75 percent of their credit limit (Figure 18). By comparison, only 39 percent of adults ages 50 to 59, but 71.1 percent of those ages 70 to 79 and 84.3 percent of those ages 80 to 89 had borrowed less than half of their credit limit. While credit utilization changed little over time for those under age 70, it increased slightly for those ages 70 and older. Between 2010 and 2019, for example, the proportion of older adults with credit utilization rates of at least 50 percent increased from 28.9 to 34.5 percent for $70-79$ year-olds and from 15.7 to 19.9 percent for $80-89$ year-olds. Thus their capacity to borrow has declined over time.

\section{Sources of Debt Associated with Financial Health}

People can fall into poor credit for many personal reasons, such as a job loss, divorce or widowhood, or a catastrophic health event. Oftentimes these events lead them to make late debt payments or look into taking out loans or open new credit cards. When credit companies see delinquencies, inquiries, and new credit lines, this often results in lower credit scores. We examined the likelihood of falling into poor credit among those with good credit in 2010 . We define poor credit as having near prime or subprime credit scores - that is, credit scores of 660 or lower. Between 2011 and 2019, we find that 21.3 percent of all older adults experienced at least one spell of poor credit-14.4 percent experience one spell, 5 percent experience two spells, and less than 1 percent experience 3 or more spells (Table 3). Both the youngest and oldest in our sample have the highest likelihoods of experiencing spells of poor credit, with 22.8 percent of 50-59 year-olds and 22.3 percent of 80-89 year-olds experiencing at least one spell of poor credit between 2011 and 2019. This contrasts with 18.5 percent of 70-79 year-olds and 17.9 percent of 60-69 year-olds. There are also large differences by zip-code characteristics - with residents in low-income zip codes and high nonwhite zip codes more likely to experience spells of poor credit than their counterparts. For example, 26.7 percent of residents in low-income zip codes 
experience spells of poor credit compared with only 16.6 percent of their counterparts in highincome zip codes. In addition, residents in low-income zip codes are more likely than those in high-income zip codes to experience multiple spells.

The average spell duration among those who experience spells of poor credit is 2.4 years. Nearly half (49.2 percent) of older adults have spells lasting up to a year, but 15.3 percent have spells that last 5 or more years. ${ }^{3}$ Residents in low-income zip codes and those in high nonwhite zip codes are least likely to have spells of only one year and most likely to have spells lasting at least 5 years. For example, 46.7 percent of residents in low-income zip codes have spells of only a year, but 17.1 percent have spells of 5 or more years. In contrast, 51.7 percent of residents in high-income zip codes have spells of one year, but only 13.5 percent have spells of 5 or more years.

Next we consider the relationship between sources of debt and spells of poor credit. ${ }^{4}$ Models 1 and 2 examine the likelihood of entering a poor credit spell, while Models 3 and 4 examine the likelihood of exiting a poor credit spell (Table 4). The models control for the value of debt (in \$10,000) from different sources, as well for age, year, state of residence, and zip code characteristics.

Of the sources of debt we examine in Model 1, credit card debt is the most correlated with the likelihood of falling into poor credit, followed by medical collections, nonmedical collections, student loans, other debt, and mortgage debt. A $\$ 10,000$ increase in credit card balances is correlated with an increase in the likelihood of falling into poor credit of nearly 5 percentage points. The amount of medical collections and nonmedical collections also has a relatively highly association with the probability of experiencing poor credit. A $\$ 10,000$ increase in the medical collections relates to a 3.8 percentage point increase in the likelihood of poor credit. Student loans and mortgage debt are also positively correlated with the probability of experiencing poor credit, but the association is significantly smaller.

\footnotetext{
${ }^{3}$ Our data are annual snapshots. While some spells could last less than a year, we can only be certain that they didn't last more than a year.

${ }^{4}$ Our choice of control variables is limited because the credit bureau data does not include personal information, other than age, that might predict credits scores and changes in credit scores. We are further limited because many of the variables in the credit bureau data, such as delinquencies, inquiries, and recency of new credit, are used by the credit bureau models to generate credit scores. Because these and many of the other variables in the credit bureau data we have access to are highly correlated with credit scores, we exclude them from our models and focus on the sources of debt and how they correlate with credit scores, rather than attempt to establish causality.
} 
Because credit scores are highly correlated with collections, Model 2 excludes older adults who ever had debt in collections and focuses on the sources of debt outside of collections that may influence poor credit. Again, credit card debt is the most correlated with the likelihood of falling into poor credit. A $\$ 10,000$ increase in credit card balances relates to a 4 percentage point increase in the probability of experiencing poor credit. Student loans, other debt, and mortgage debt (in that order) are also positively correlated with poor credit. In contrast, auto loans are negatively correlated with poor credit. However, the correlation is significantly smaller and weaker than the other sources of debt.

Next we examine the relationship between sources of debt and the likelihood of exiting from poor credit spells. As expected, nearly all sources of debt we capture have a negative relationship with exiting poor credit spells. That is, the larger the value of debt the less likely one will improve their credit score enough to move into a good credit rating. In Model 3, credit card debt is the most correlated with the likelihood of exiting poor credit, followed by medical collections, nonmedical collections, student loans, other debt, and mortgage debt. A $\$ 10,000$ increase in credit card debt is associated with a 3.3 percentage point reduction in the probability of exiting a spell of poor credit, and a $\$ 10,000$ increase in medical collections is associated with a 1.7 percentage point reduction in exiting poor credit.

Excluding older adults who ever had debt in collections in Model 4, credit card debt still is the most correlated with exiting poor credit. A $\$ 10,000$ increase in credit card debt is related to a 3.9 percentage point reduction in the probability of exiting poor credit. Mortgage debt has a larger influence on the odds of escaping from poor credit than it does on the likelihood of falling into poor credit. For example, a $\$ 100,000$ increase in mortgage debt is correlated with a 1.3 percentage point reduction in exiting poor credit. Again, auto loans have the opposite effect on exiting poor credit than the other sources of debt we examine. This may reflect that for many financially disadvantaged adults, automobiles are not luxuries. Instead, they are necessities for working to escape their dire circumstances. However, the correlation is significantly smaller and weaker than the other sources of debt.

\section{Discussion}

As Americans have become increasingly indebted over time, understanding the factors influencing indebtedness is increasingly important and can help policymakers design policies 
that discourage debt, thus enhancing private retirement savings so that retirees become less dependent on Social Security benefits. Using data from a major credit bureau, we find that older Americans have become decreasingly indebted since the Great Recession. This trend, however, may be at least partly driven by population aging as people generally deleverage as they age. Moreover, it masks the increase in indebtedness among older adults after age 70. Not only are they more indebted, but our findings suggest that their financial health — reflected by their credit scores and capacity to borrow-has also worsened over time.

We further find that where people live matters for their use of debt at older ages. Older adults from socioeconomically disadvantaged areas carry debt well into their retirement years, whereas those who live in wealthier zip codes appear to deleverage as they age. This finding suggests that older adults who are less well-off may heavily rely on debt to support their standard of living in retirement.

Finally, we find that, more than other sources of debt, credit card debt is the most highly correlated with spells of poor credit - increasing both the likelihood of experiencing a spell and reducing the likelihood of exiting a spell. This has negative implications for consumers ages 70 and older since credit cards are their largest source of non-mortgage debt.

The rise in debt among the oldest Americans is especially concerning because the likelihood of experiencing a negative event that jeopardizes ones' financial security increases with age. The onset of health problems, losing a job, or becoming widowed or divorced can have serious negative effects on retirement savings. Johnson, Mermin, and Uccello (2006) find that more than two-thirds of those age 70 and older experience a negative event over a nine- or 10-year period and simultaneously a large decline in wealth. High levels of debt could exacerbate the impact of any impending negative shocks. 


\section{References}

Almenberg, Johan, Annamaria Lusardi, Jenny Säve-Söderbergh, and Roine Vestman. 2018. Attitudes Toward Debt and Debt Behavior. Working paper no. w24935. National Bureau of Economic Research.

Archuleta, Kristy L., Anita Dale, and Scott M. Spann. 2013. "College Students and Financial Distress: Exploring Debt, Financial Satisfaction, and Financial Anxiety." Journal of Financial Counseling and Planning 24(2): 50-62.

Bell, Mary, Jeffrey Nelson, Scott Spann, Callie Molloy, Sonya Britt, and Briana Goff. 2014. "The Impact of Financial Resources on Soldiers' Well-Being." Journal of Financial Counseling and Planning 25(1): 41-52.

Board of Governors of the Federal Reserve System. 2019. "Report on the Economic Well-Being of U.S. Households in 2018." Washington, DC: Board of Governors of the Federal Reserve System.

Brown, Jason, Karen E. Dynan, and Theodore F. Figinski. 2019. "The Risk of Financial Hardship in Retirement: A Cohort Analysis." Wharton Pension Research Council Working Paper 2019-10.

Brown, Meta, Donghoon Lee, Joelle Scally, and Wilbert van der Klaauw. 2019. "The Graying of American Debt." Wharton Pension Research Council Working Paper 2019-09.

Brown, Meta, and Matthew Mazewski. 2016. "Stepping Stone or Quicksand? The Role of Consumer Debt in the US Geography of Economic Mobility." In: Brown, Alexandra, David Buchholz, Daniel Davis, and Arturo Gonzalez (eds.), Economic Mobility: Research and Ideas on Strengthening Families, Communities, and the Economy. St. Louis, MO: Federal Reserve Bank of St. Louis and Board of Governors of the Federal Reserve System.

Brown, Sarah, Karl Taylor, and Stephen Wheatley Price. 2005. "Debt and Distress: Evaluating the Psychological Cost of Credit." Journal of Economic Psychology 26(5): 642-663.

Butrica, Barbara A. and Nadia S. Karemcheva. 2018. "In Debt and Approaching Retirement: Claim Social Security or Work Longer.” AEA Papers and Proceedings 108: 401-406.

Butrica, Barbara A. and Stipica Mudrazija. 2016. "Home Equity Patterns among Older American Households." Washington, DC: Urban Institute.

Butrica, Barbara A., and Nadia S. Karamcheva. 2013. "Does Household Debt Influence the Labor Supply and Benefit Claiming Decisions of Older Americans?" Working paper 2013-22. Chestnut Hill, MA: Center for Retirement Research.

Collinson, Catherine, Patti Rowey, and Heidi Cho. 2020. Retirement Security Amid COVID-19: The Outlook of Three Generations. Transamerica Center for Retirement Studies. 
Consumer Financial Protection Bureau. 2017. "Snapshot of Older Consumers and Student Loan Debt." Washington, DC: Office for Older Americans and Office for Students and Young Consumers, Consumer Financial Protection Bureau.

de Bassa Scheresberg, Carlo, and Annamaria Lusardi. 2014. "Financial Capability Near Retirement: A Profile of Pre-Retirees." Filene Research Institute Report.

Dobbie, Will, Paul Goldsmith-Pinkham, and Crystal S. Yang. 2017. "Consumer Bankruptcy and Financial Health." Review of Economics and Statistics 99(5): 853-869.

Dobbie, Will, and Jae Song. 2015. "Debt Relief and Debtor Outcomes: Measuring the Effects of Consumer Bankruptcy Protection." American Economic Review 105(3): 1272-1311.

Drentea, Patricia, and John R. Reynolds. 2012. "Neither a Borrower nor a Lender Be: The Relative Importance of Debt and SES for Mental Health among Older Adults." Journal of Aging and Health 24(4): 673-695.

Ebrahimi, Zahra. 2020. "The Impact of Rising Household Debt Among Older Americans." EBRI Issue Brief 502.

Elliott, William, Michal Grinstein-Weiss, and Ilsung Nam. 2013. "Student Debt and Declining Retirement Savings.” CSD Working Paper No. 13-34. St. Louis, MO: Center for Social Development.

Elliott, William, Michal Grinstein-Weiss, and Ilsung Nam. 2013b. "Does Outstanding Student Debt Reduce Asset Accumulation?” CSD Working Paper No. 13-32. St. Louis, MO: Center for Social Development.

Federal Reserve Bank of New York. 2019. "Quarterly Report on Household Debt and Credit: 2018: Q4.” New York, NY.

Federal Reserve Bank of New York. 2020. “Quarterly Report on Household Debt and Credit: 2019: Q4.” New York, NY.

Fichtner, Jason J. 2019. "Household Debt and Financial Well-Being in Retirement." Working Paper WI19-10. Madison, WI: Center for Financial Security.

Fitch, Chris, Sarah Hamilton, Paul Bassett, and Ryan Davey. 2011. "The Relationship Between Personal Debt and Mental Health: A Systematic Review." Mental Health Review Journal 16(4):153-166.

Fry, Richard. 2013. "Young Adults After the Recession: Fewer Homes, Fewer Cars, Less Debt." Washington, DC: Pew Research Center. 
Government Accountability Office. 2014. "Older Americans: Inability to Repay Student Loans May Affect Financial Security of a Small Percentage of Retirees." Testimony Before the Special Committee on Aging, U.S. Senate. GAO-14-866T. Washington, DC: United States Government Accountability Office.

Greenberg, Adam Eric, and Cassie Mogilner. 2020. " Consumer Debt and Satisfaction in Life." Journal of Experimental Psychology: Applied. Advance online publication. DOI: 10.1037/xap0000276.

Hamilton, Hayley A., Christine M. Wickens, Anca R. Ialomiteanu, and Robert E. Mann. 2019. "Debt Stress, Psychological Distress and Overall Health Among Adults in Ontario." Journal of psychiatric research 111: 89-95.

Heisler, Michele, Todd H. Wagner, and John D. Piette. 2005. "Patient Strategies to Cope with High Prescription Medication Costs: Who Is Cutting Back on Necessities, Increasing Debt, or Underusing Medications?" Journal of Behavioral Medicine 28(1): 43-51.

Hodson, Randy, Rachel E. Dwyer, and Lisa A. Neilson. 2014. "Credit Card Blues: The Middle Class and The Hidden Costs of Easy Credit." The Sociological Quarterly 55(2): 315-340.

Hojman, Daniel A., Álvaro Miranda, and Jaime Ruiz-Tagle. 2016. "Debt trajectories and mental health." Social Science \& Medicine 167: 54-62.

Johnson, Richard W., Gordon B.T. Mermin, and Cori E. Uccello. 2006. "When the Nest Egg Cracks: Financial Consequences of Health Problems, Marital Status Changes, and Job Layoffs at Older Ages." Washington, DC: Urban Institute.

Joint Center for Housing Studies of Harvard University. 2014. "Housing America's Older Adults: Meeting the Needs of an Aging Population." Cambridge, MA: Joint Center for Housing Studies of Harvard University.

Kim, Jinhee, and Swarn Chatterjee. 2019. "Student Loans, Health, and Life Satisfaction of US Households: Evidence from a Panel Study." Journal of Family and Economic Issues 40(1): 36-50.

Leung, Leigh Ann, and Catherine Lau. 2017. "Effect of Mortgage Indebtedness on Health of US Homeowners." Review of Economics of the Household 15(1): 239-264.

Li, Zhe. 2019. "Household Debt Among Older Americans, 1989-2016." Washington, DC: Congressional Research Service. 
Lusardi, Annamaria, Olivia S. Mitchell, and Noemi Oggero. 2020. "Debt and Financial Vulnerability on the Verge of Retirement." Journal of Money, Credit and Banking 52(5): 1005-1034.

Lusardi, Annamaria, Olivia S. Mitchell, and Noemi Oggero. 2018. "The Changing Face of Debt and Financial Fragility at Older Ages.” AEA Papers and Proceedings 108: 407-411.

Lusardi, Annamaria, and Olivia S. Mitchell. 2018. "Older Women's Labor Market Attachment, Retirement Planning, and Household Debt." In: Goldin, Claudia and Lawrence F. Katz (eds.), Women Working Longer: Increased Employment at Older Ages (pp. 185-215). Chicago, IL: University of Chicago Press.

Lusardi, Annamaria, and Olivia S. Mitchell. 2013. "Debt and Debt Management Among Older Adults." Ann Arbor, MI: Michigan Retirement Research Center.

Mann, Allison. 2011. "The Effect of Late-Life Debt Use on Retirement Decisions." Social Science Research 40(6): 1623-1637.

Masnick, George S., Zhu Xiao Di, and Eric S. Belsky. 2006. "Emerging Cohort Trends in Housing Debt and Home Equity." Housing Policy Debate 17 (3): 491-527.

Meltzer, Howard, Paul Bebbington, Traolach Brugha, Michael Farrell, and Rachel Jenkins. 2012. "The Relationship between Personal Debt and Specific Common Mental Disorders." The European Journal of Public Health 23(1): 108-113.

Moulton, Stephanie, Donald Haurin, and Caezilia Loibl. 2019. "Debt Stress and Mortgage Borrowing in Older Age: Implications for Economic Security in Retirement." Economic Inquiry 54(1): 201-214.

Munnell, Alicia H., Wenliang Hou, and Anthony Webb. 2016. "Will the Explosion of Student Debt Widen the Retirement Security Gap?" Issue Brief No. 16-2. Chestnut Hill, MA: Center for Retirement Research at Boston College.

Peter G. Peterson Foundation. 2020. "Household Debt Remains High.” Available at https://www.pgpf.org/chart-archive/0062_household-debt.

Pew Charitable Trusts. 2015. "The complex story of American debt: Liabilities in family balance sheets." Washington, DC: Pew Charitable Trusts.

Rutledge, Matthew S., Geoffrey T. Sanzenbacher, and Francis M. Vitagliano. 2016. "How Does Student Debt Affect Early-Career Retirement Saving?" CRR WP 2016-9. Boston, MA: Center for Retirement Research at Boston College.

Seay, Martin, Sarah Asebedo, Cametra Thompson, Cherie Stueve, and Ricardo Russi. 2015. "Mortgage Holding and Financial Satisfaction in Retirement." Journal of Financial Counseling and Planning 26(2): 200-216. 
Selenko, Eva, and Bernad Batinic. 2011. "Beyond Debt. A Moderator Analysis of the Relationship Between Perceived Financial Strain and Mental Health." Social Science \& Medicine 73(12): 1725-1732.

Singletary, Michelle. 2019. “Average FICO Credit Score Hits New High — Which Is Good News for Borrowers and the Economy." Washington Post. Available at https://www.washingtonpost.com/business/economy/average-fico-credit-score-hits-newhigh--which-is-good-news-for-borrowers-and-the-economy/2019/09/10/2c3c30ac-d40f11e9-86ac-0f250cc91758_story.html.

Smith, Karen E., Melissa Favreault, Barbara Butrica, and Philip Issa. 2010. Final Report: Modeling Income in the Near Term, Version 6. Washington DC: Urban Institute.

Song, Hongxun, Ruoxi Wang, Ghose Bishwajit, Jie Xiong, Zhanchun Feng, and Hang Fu. 2020. "Household Debt, Hypertension and Depressive Symptoms for Older Adults." International Journal of Geriatric Psychiatry 35:779-784.

Stanford Center on Longevity. 2018. "Seeing Our Way to Financial Security in the Age of Increased Longevity." Available at http://longevity.stanford.edu/wpcontent/uploads/2018/10/Sightlines-Financial-Security-Special-Report-2018.pdf.

Stark, Ellen. 2018. "Expanding Retirement Security Through Public and Private Innovation." Aspen Institute Financial Security Program Report. Available at https://assets.aspeninstitute.org/content/uploads/2018/08/2018_RetirementSavingsReport. pdf.

Sweet, Elizabeth, Arijit Nandi, Emma K. Adam, and Thomas W. McDade. 2013. "The High Price of Debt: Household Financial Debt and Its Impact on Mental and Physical Health." Social Science \& Medicine 91: 94-100.

Tay, Louis, Cassondra Batz, Scott Parrigon, and Lauren Kuykendall. 2017. "Debt and Subjective Well-Being: The Other Side of the Income-Happiness Coin." Journal of Happiness Studies 18(3): 903-937.

Thorne, Deborah, Pamela Foohey, Robert M. Lawless, and Katherine Porter. 2018. "Graying of U.S. Bankruptcy: Fallout from Life in a Risk Society.” Indiana Legal Studies Research Paper No. 406.

Turunen, Elina, and Heikki Hiilamo. 2014. "Health Effects of Indebtedness: A Systematic Review." BMC Public Health 14(1): 489.

West, Colin P., Tait D. Shanafelt, and Joseph C. Kolars. 2011. "Quality of Life, Burnout, Educational Debt, and Medical Knowledge Among Internal Medicine Residents." Journal of the American Medical Association 306(9): 952-960. 
Zurlo, Karen A., WonAh Yoon, and Hyungsoo Kim. 2014. "Unsecured Consumer Debt and Mental Health Outcomes in Middle-Aged and Older Americans." Journals of Gerontology Series B: Psychological Sciences and Social Sciences 69(3): 461-469. 


\section{Figures}

Figure 1. Percentage of Adults Ages 50-89 With Debt and Median Debt Among Those with Debt (Thousands of 2019 Dollars)

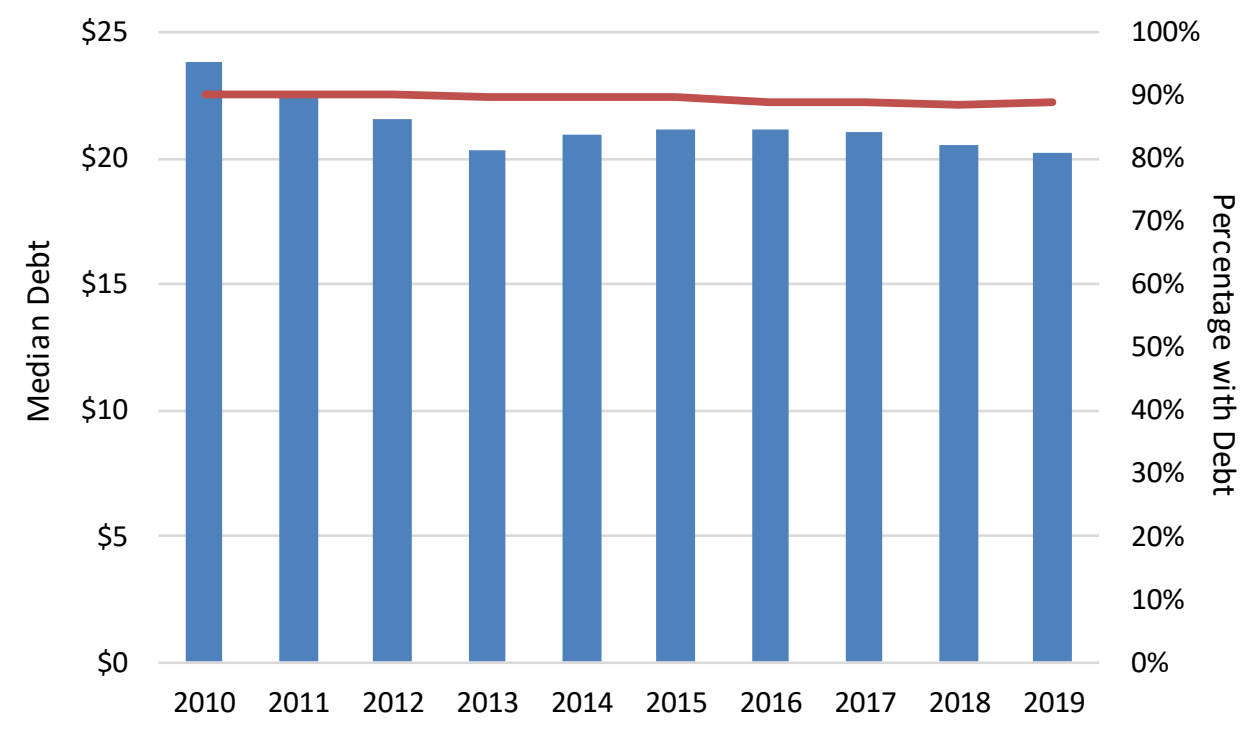


Figure 2. Percentage of Adults Ages 50 to 89 with Debt
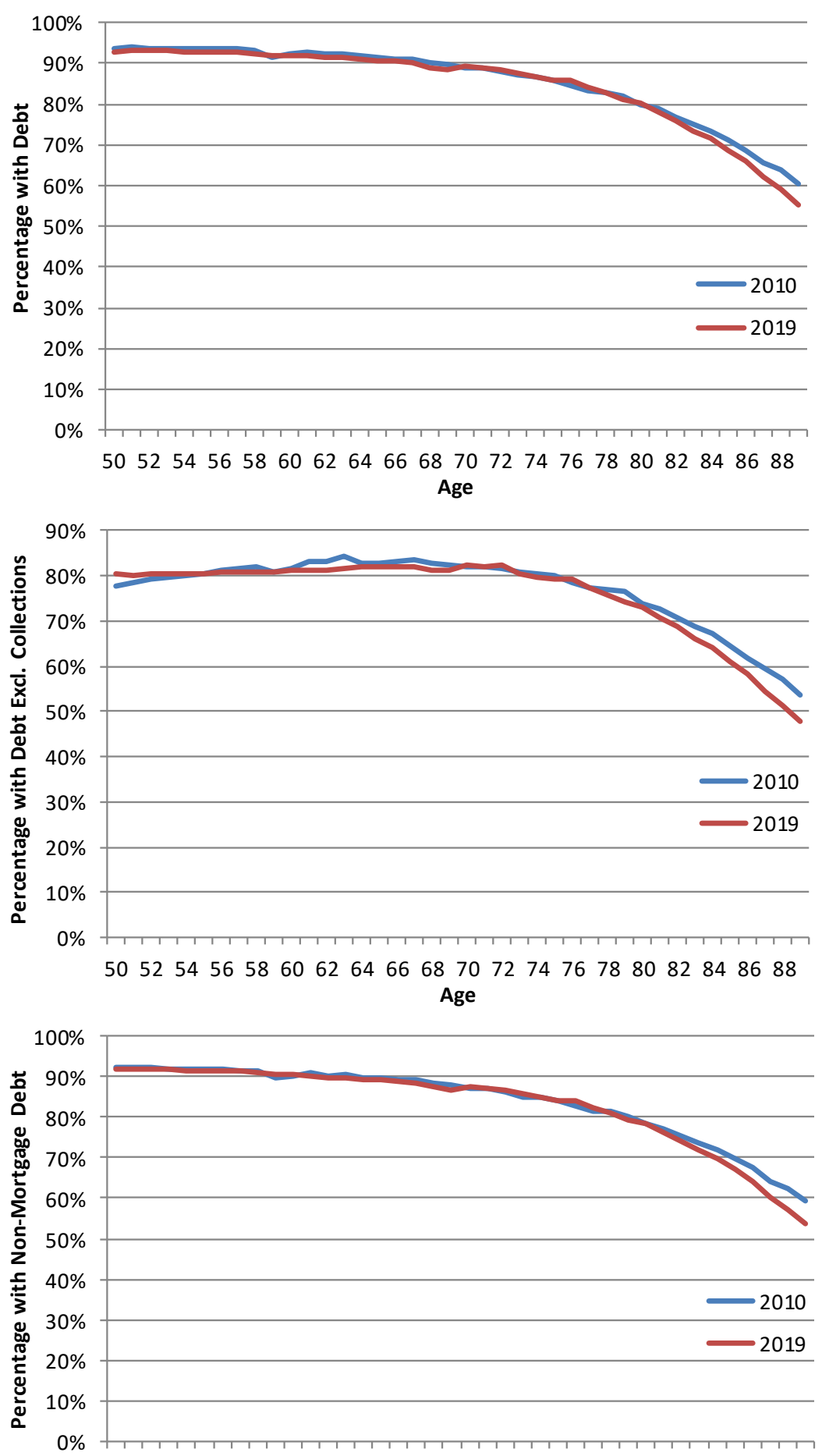

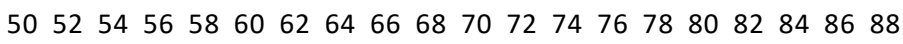
Age 
Figure 3. Median Debt Among Adults Ages 50 to 89 with Debt (Thousands of 2019 Dollars)
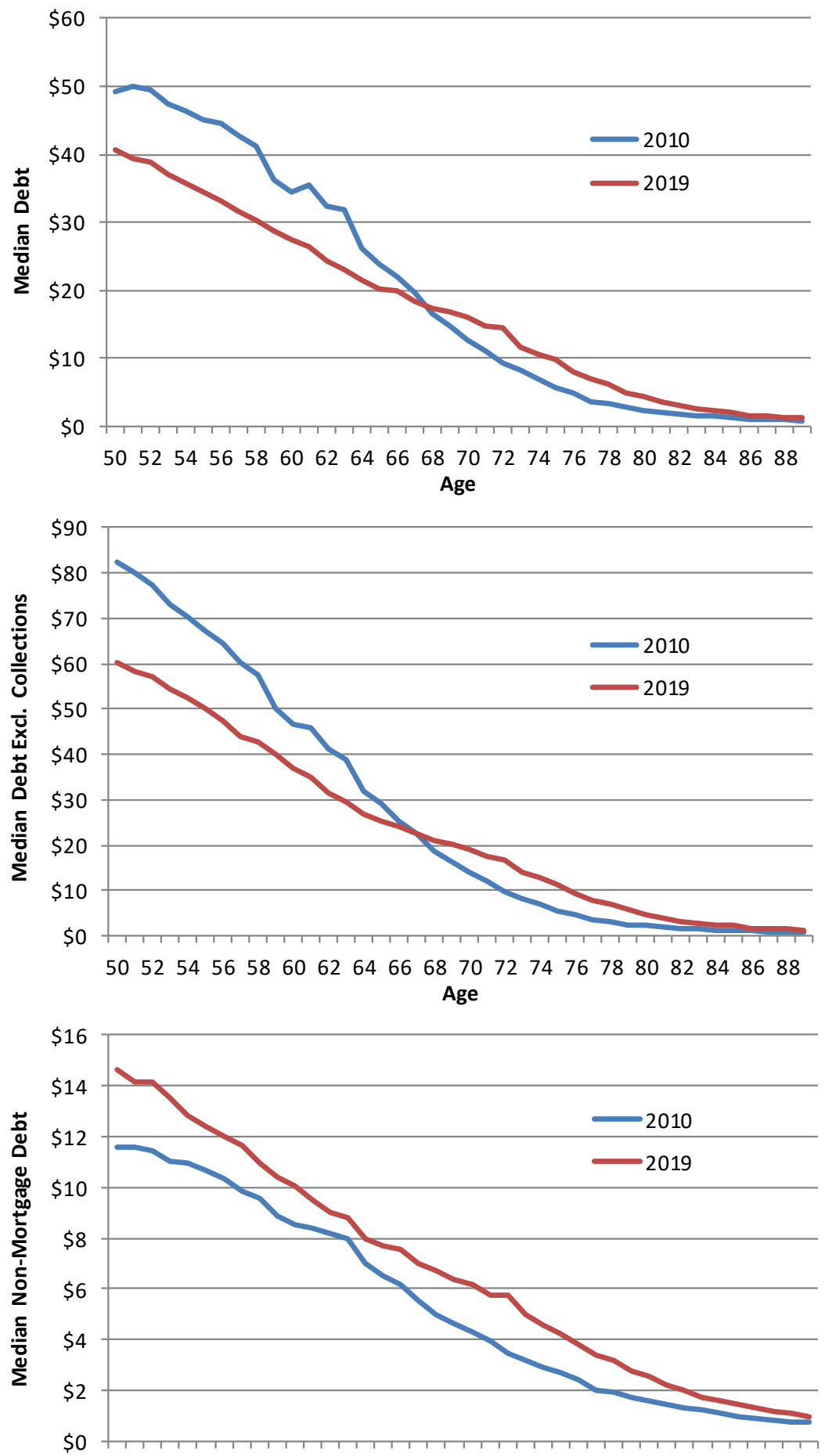

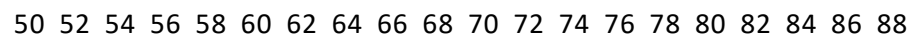
Age 
Figure 4a. Percentage of Adults Ages 50 to 89 with Mortgage Debt

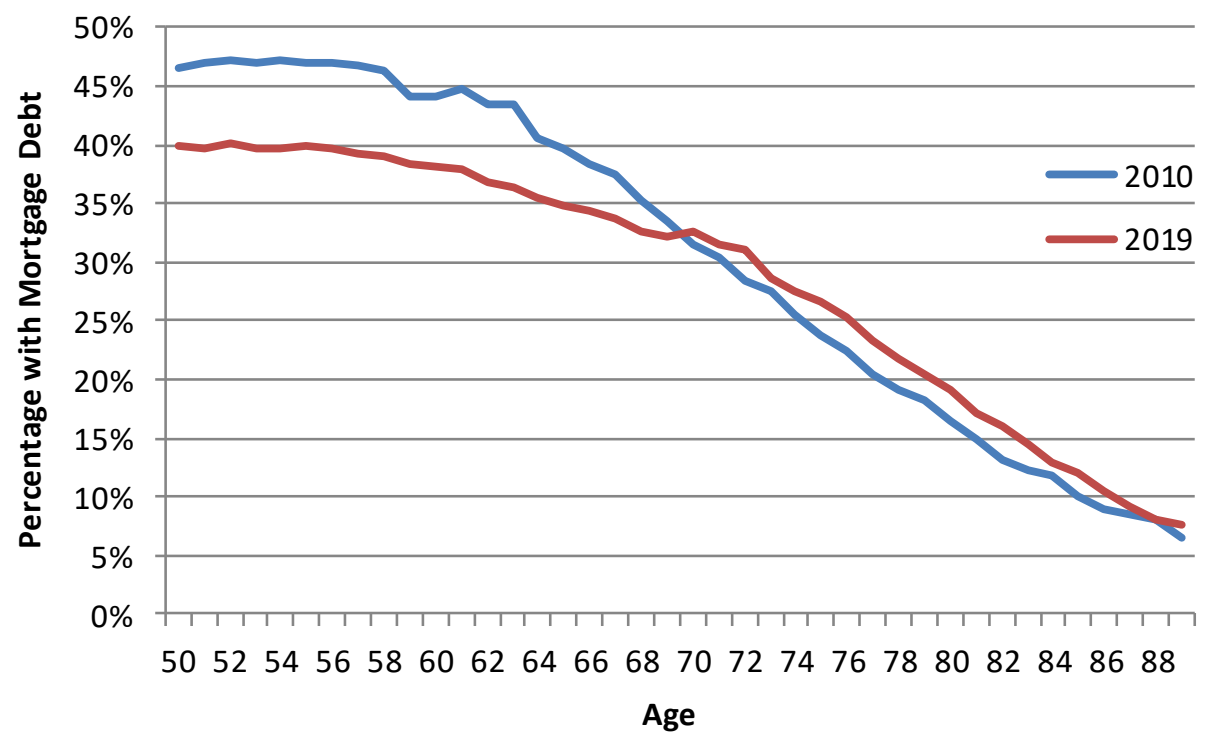

Figure 4b. Percentage of Adults Ages 50 to 89 with Credit Card Debt

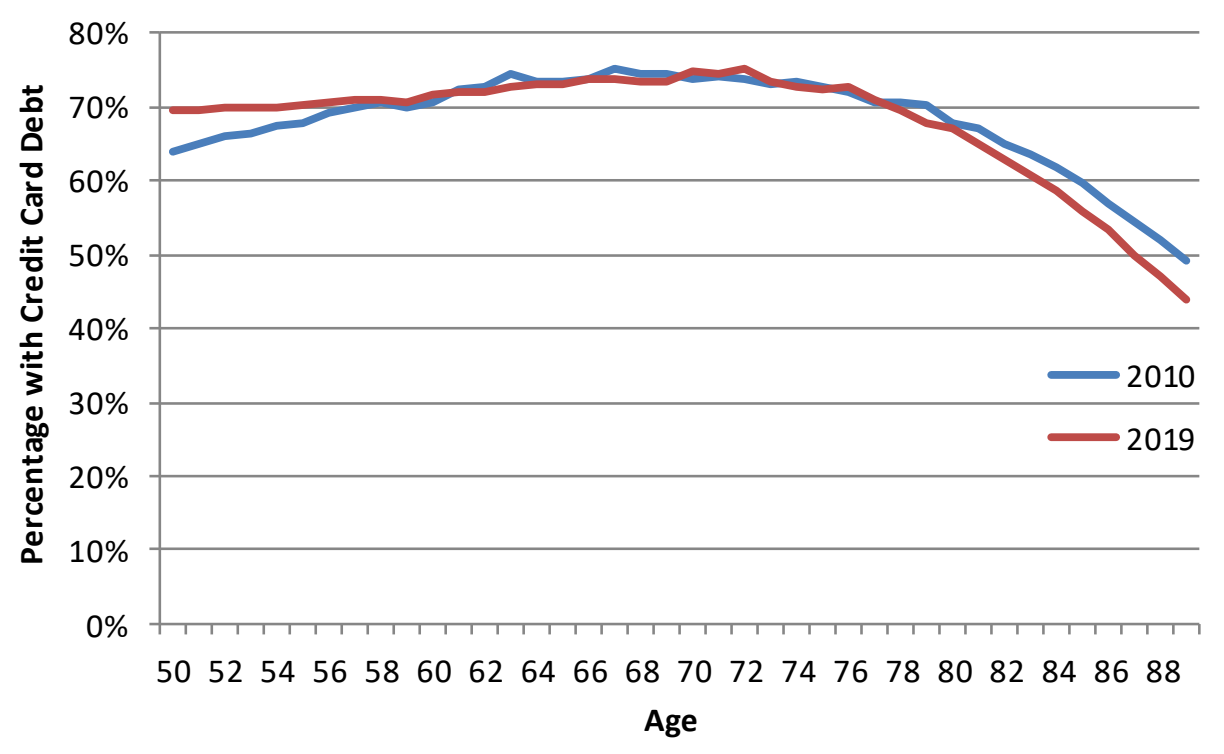


Figure 4c. Percentage of Adults Ages 50 to 89 with Auto Loans

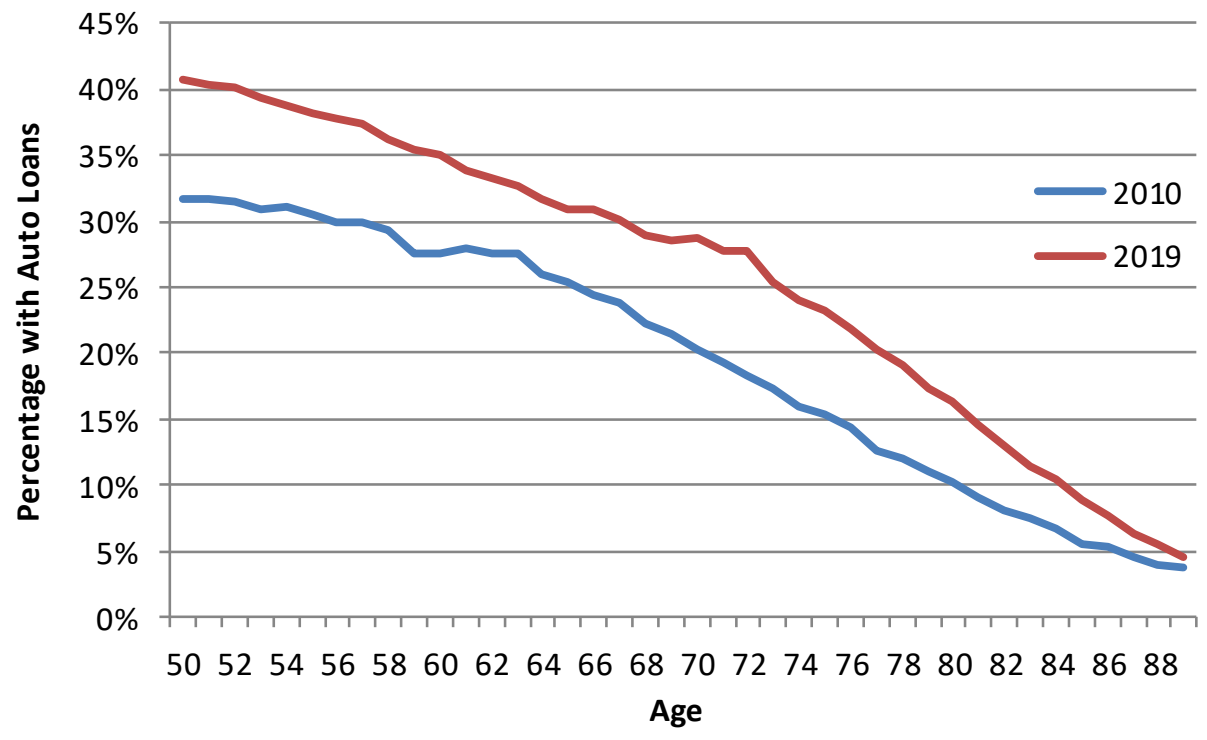

Figure 4d. Percentage of Adults Ages 50 to 89 with Student Loans

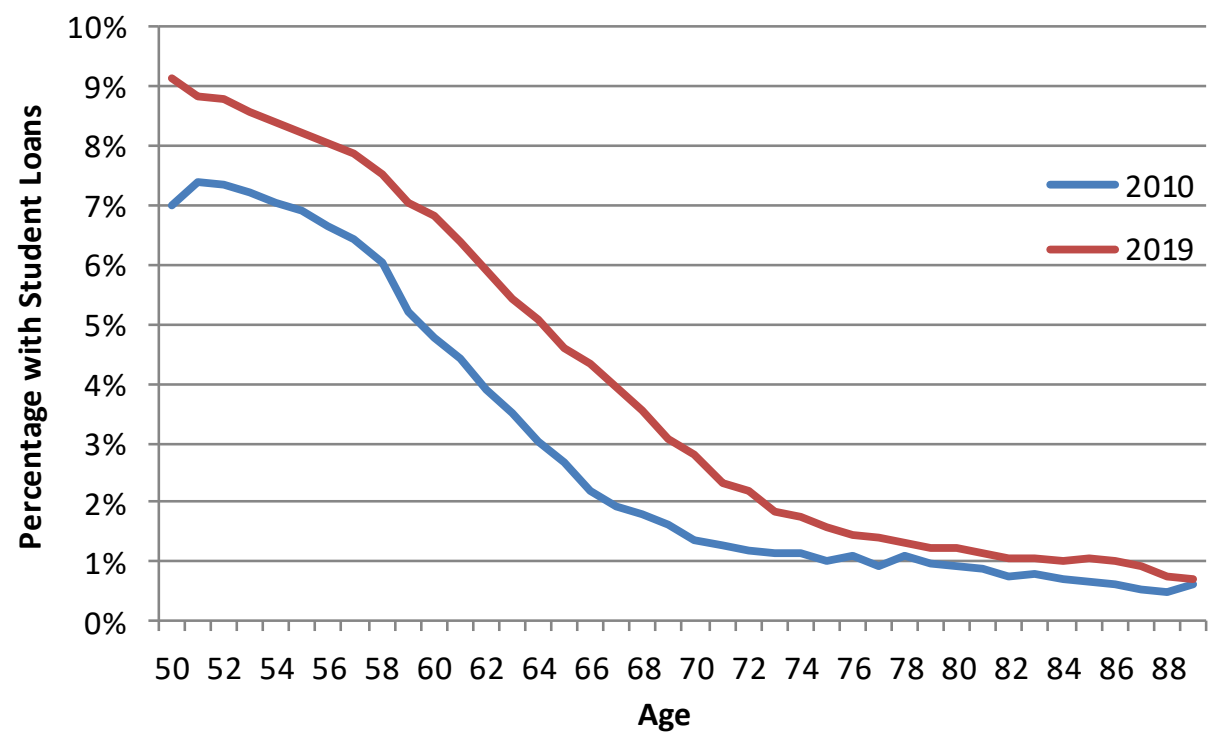


Figure 4e. Percentage of Adults Ages 50 to 89 with Other Debt

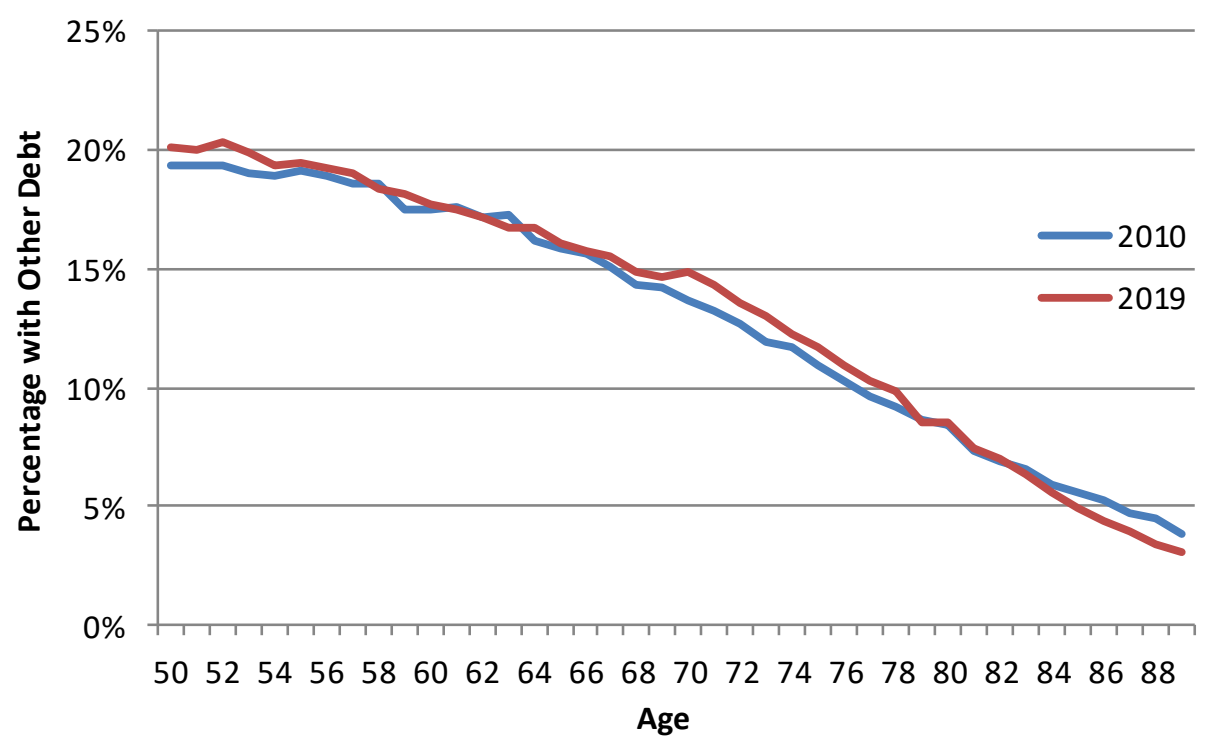

Figure 4f. Percentage of Adults Ages 50 to 89 with Debt in Collections

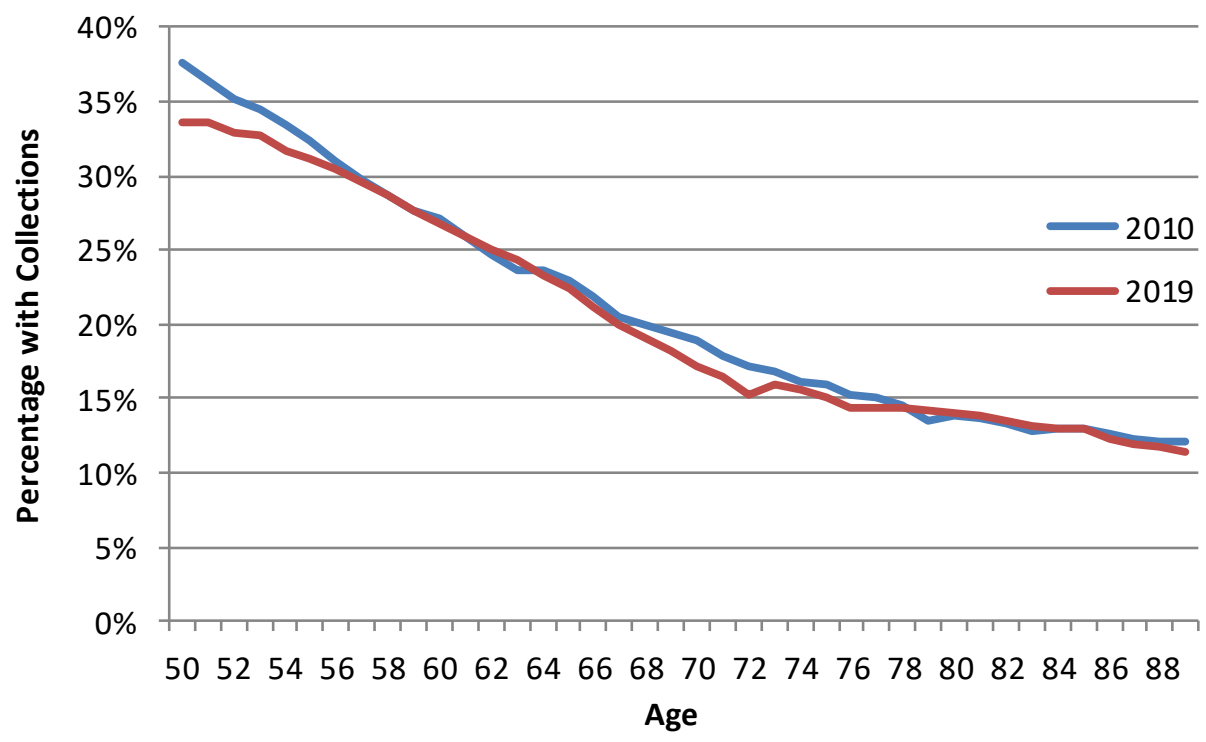


Figure 5a. Median Value of Mortgages Among Adults Ages 50 to 89 with Mortgages (Thousands of 2019 Dollars)

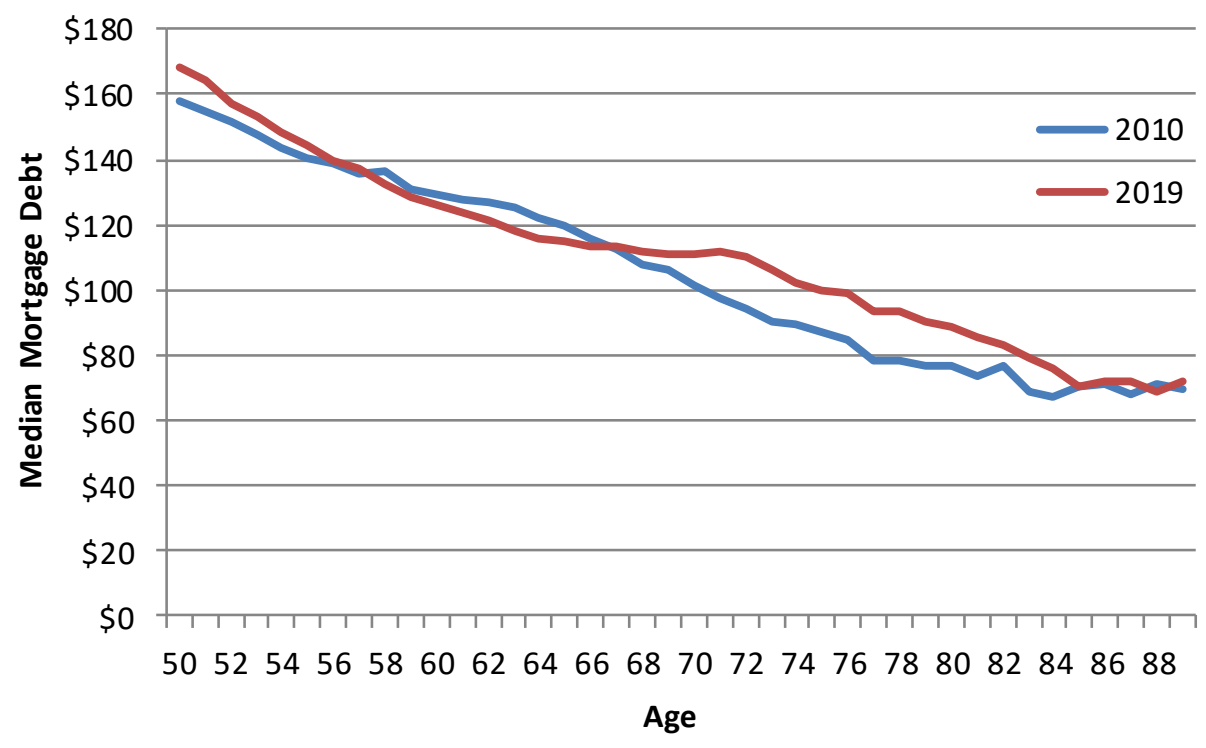

Figure 5b. Median Value of Credit Card Debt Among Adults Ages 50 to 89 with Credit Card Debt (Thousands of 2019 Dollars)

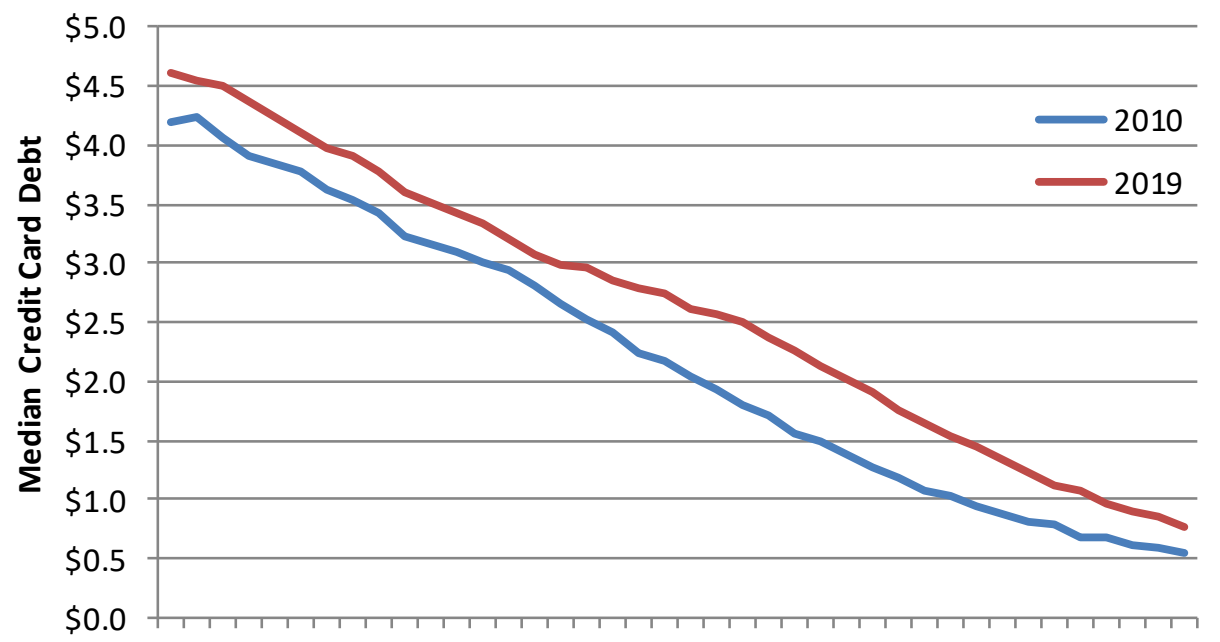

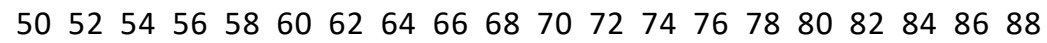
Age 
Figure 5c. Median Value of Auto Loans Among Adults Ages 50 to 89 with Auto Loans (Thousands of 2019 Dollars)

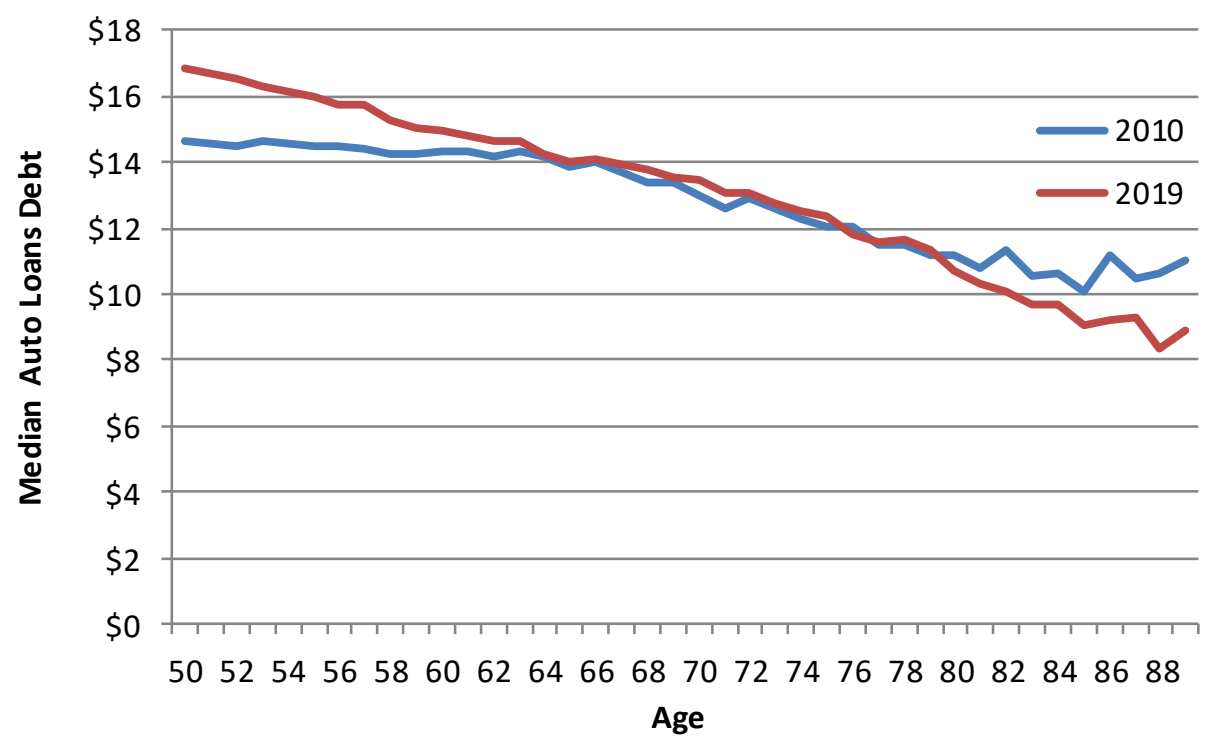

Figure 5d. Median Value of Student Loans Among Adults Ages 50 to 89 with Student Loans (Thousands of 2019 Dollars)

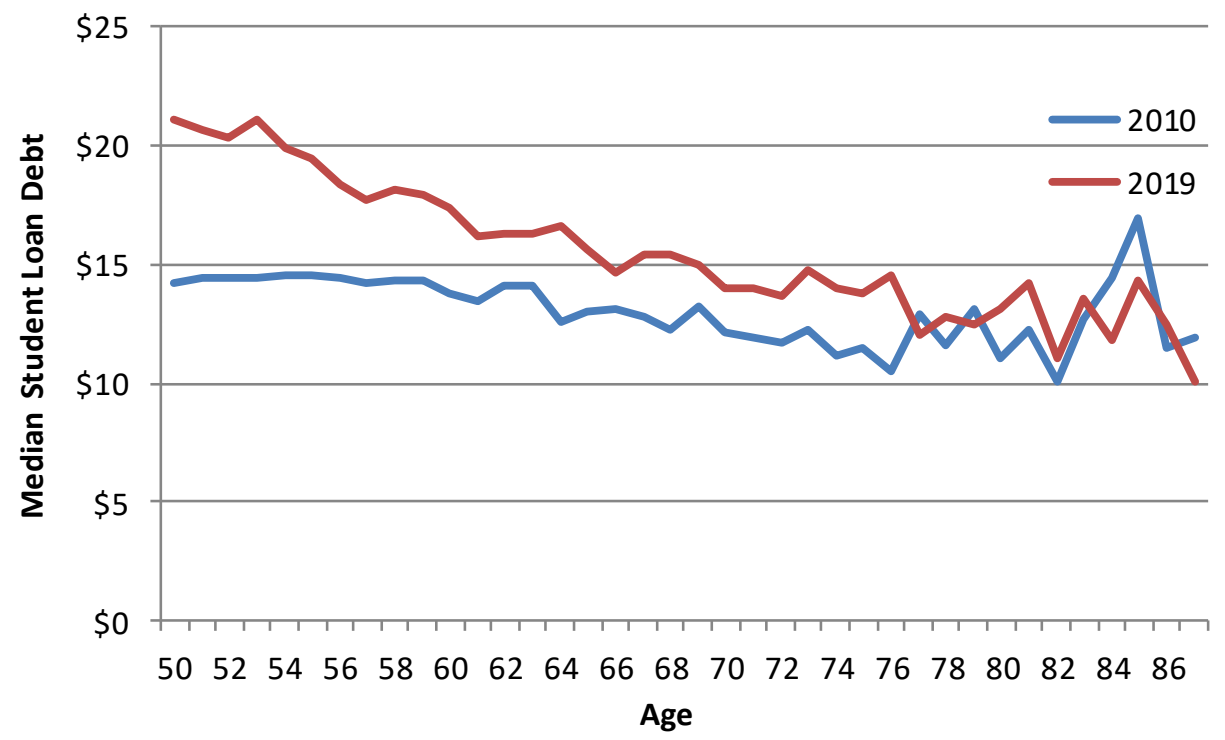


Figure 5e. Median Value of Other Debt Among Adults Ages 50 to 89 with Other Debt (Thousands of 2019 Dollars)

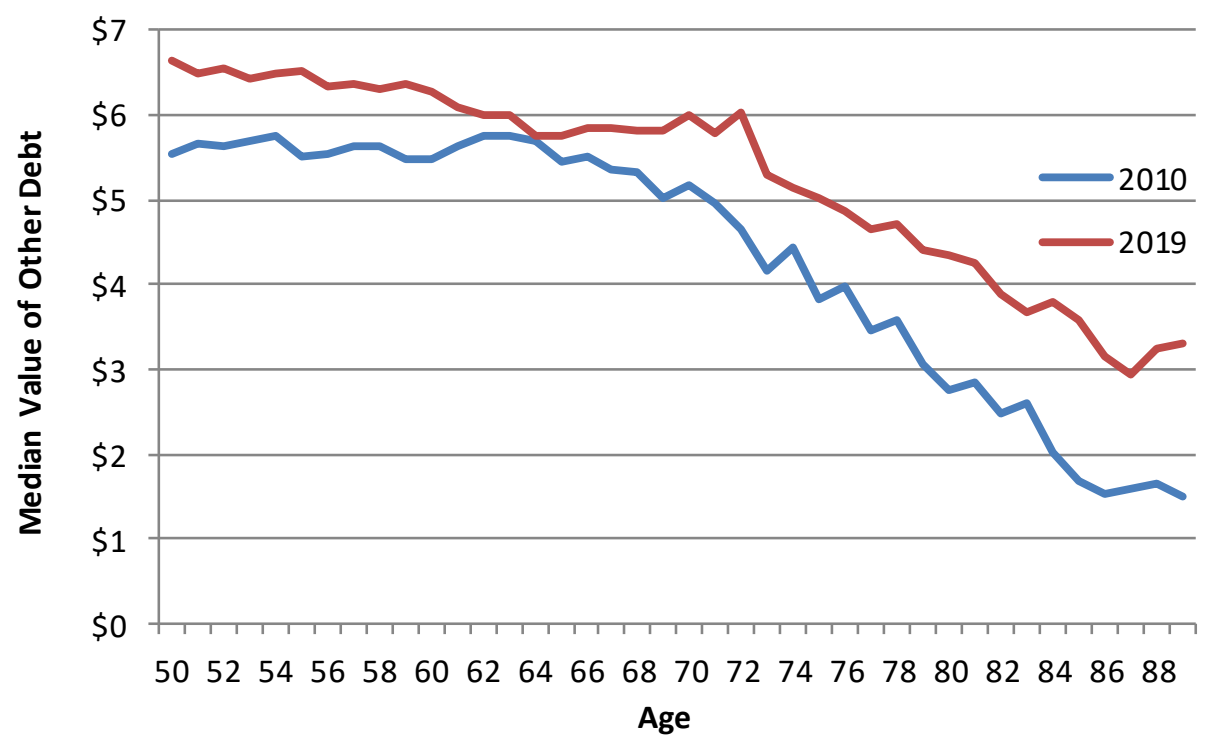

Figure 5f. Median Value of Collections Among Adults Ages 50 to 89 with Debt in Collections (Thousands of 2019 Dollars)

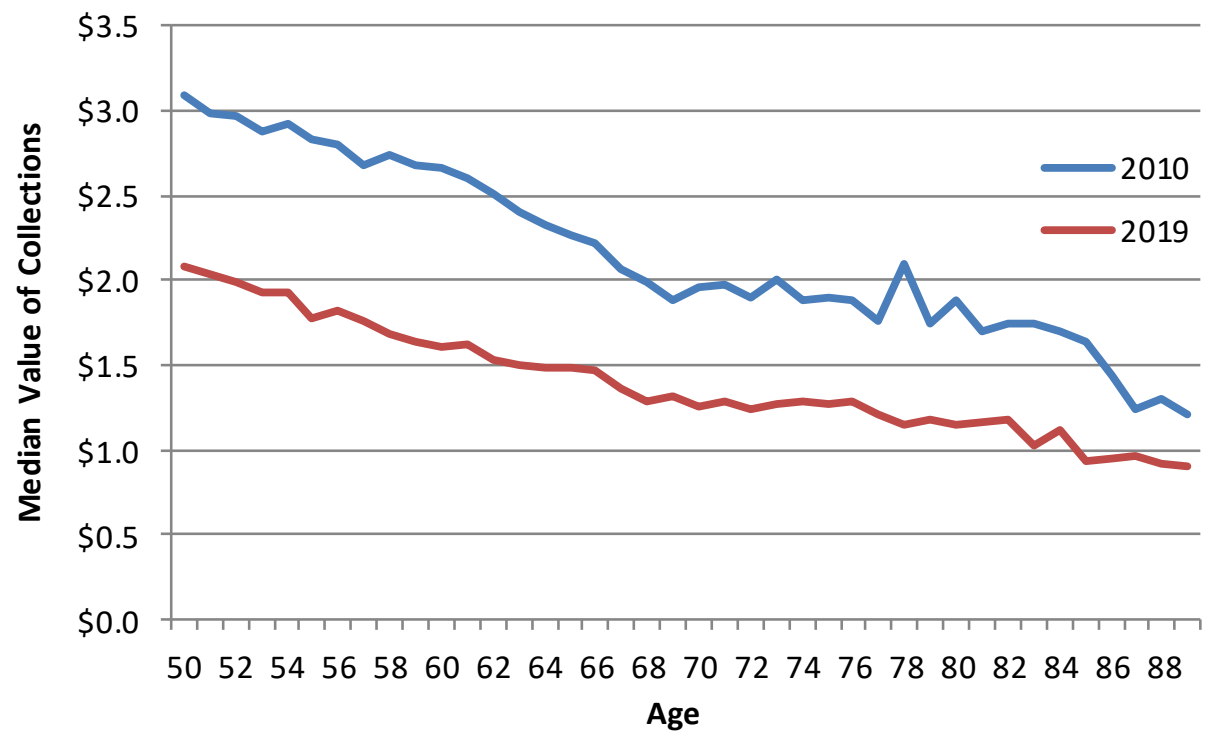


Figure 6. Mean Share of Total Debt from Sources Among Adults Ages 50 to 89 with Debt

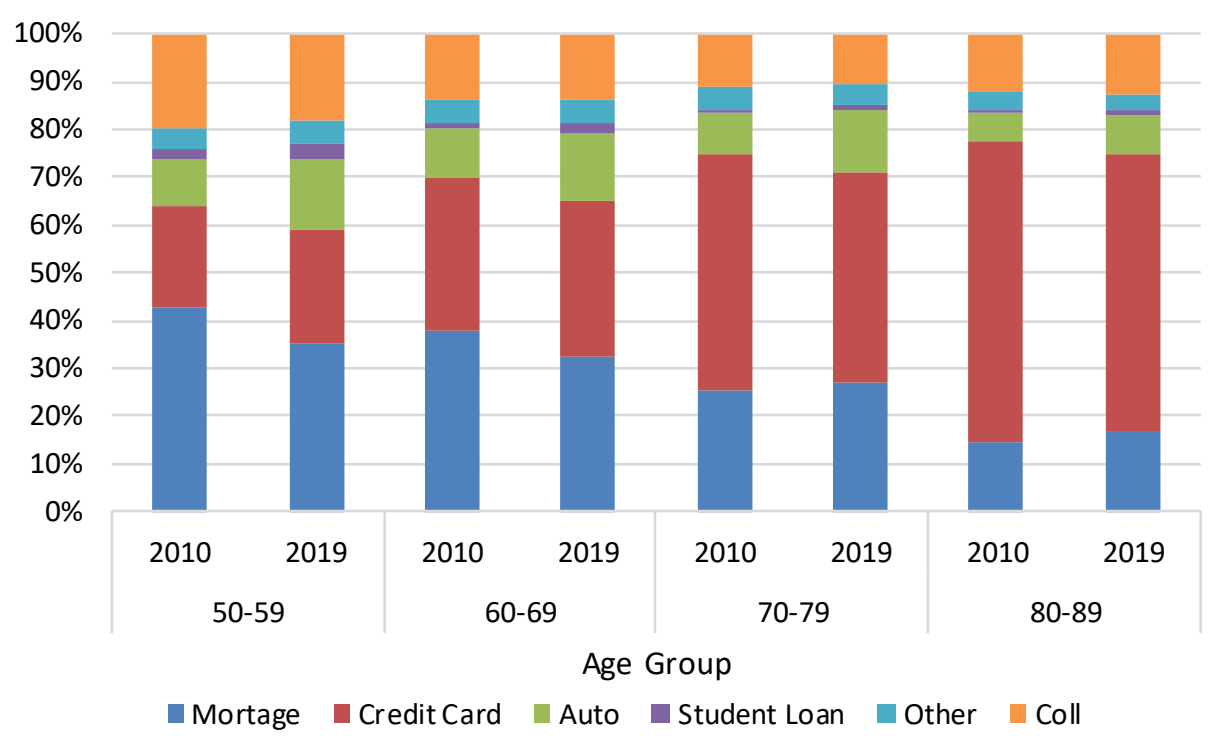

Figure 7. Median Value of Change in Debt Between 2010 and 2019 and Lowest and Highest Years (Thousands of 2019 Dollars)

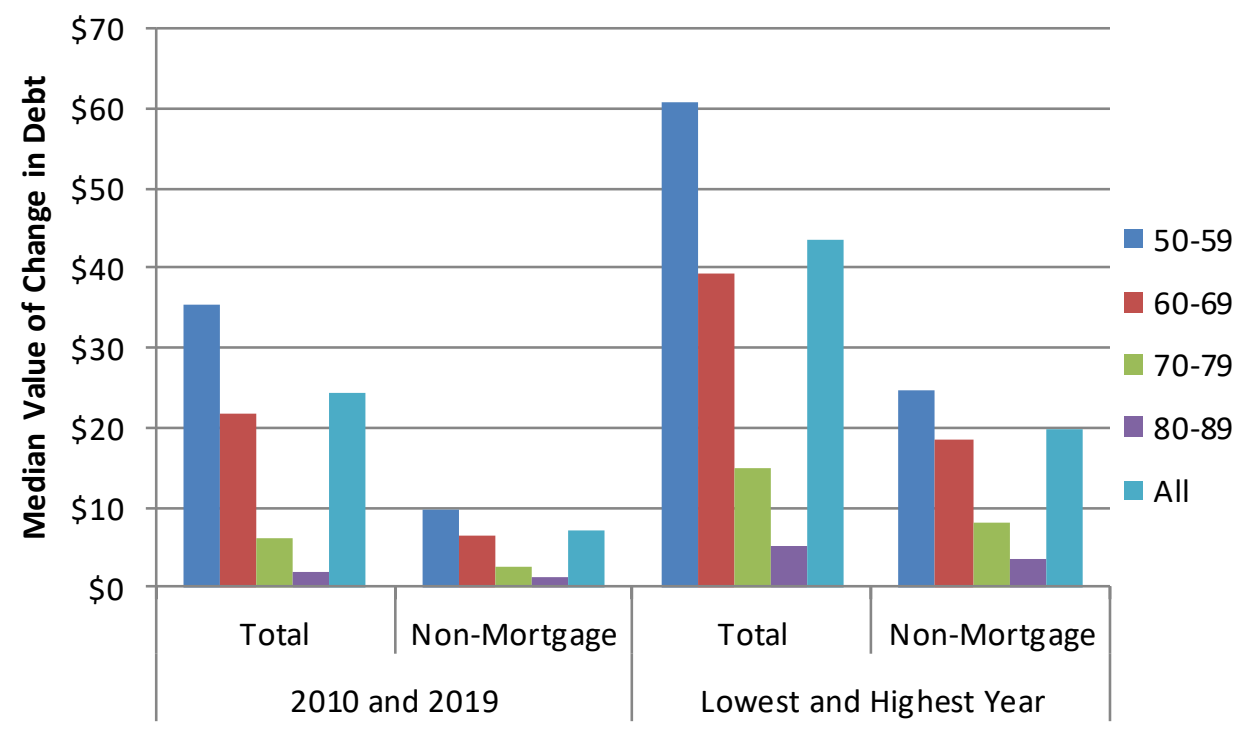


Figure 8. Median Debt Among Adults Ages 50 to 89 With Debt, by Median Household Income within Zip Codes (Thousands of 2019 Dollars)
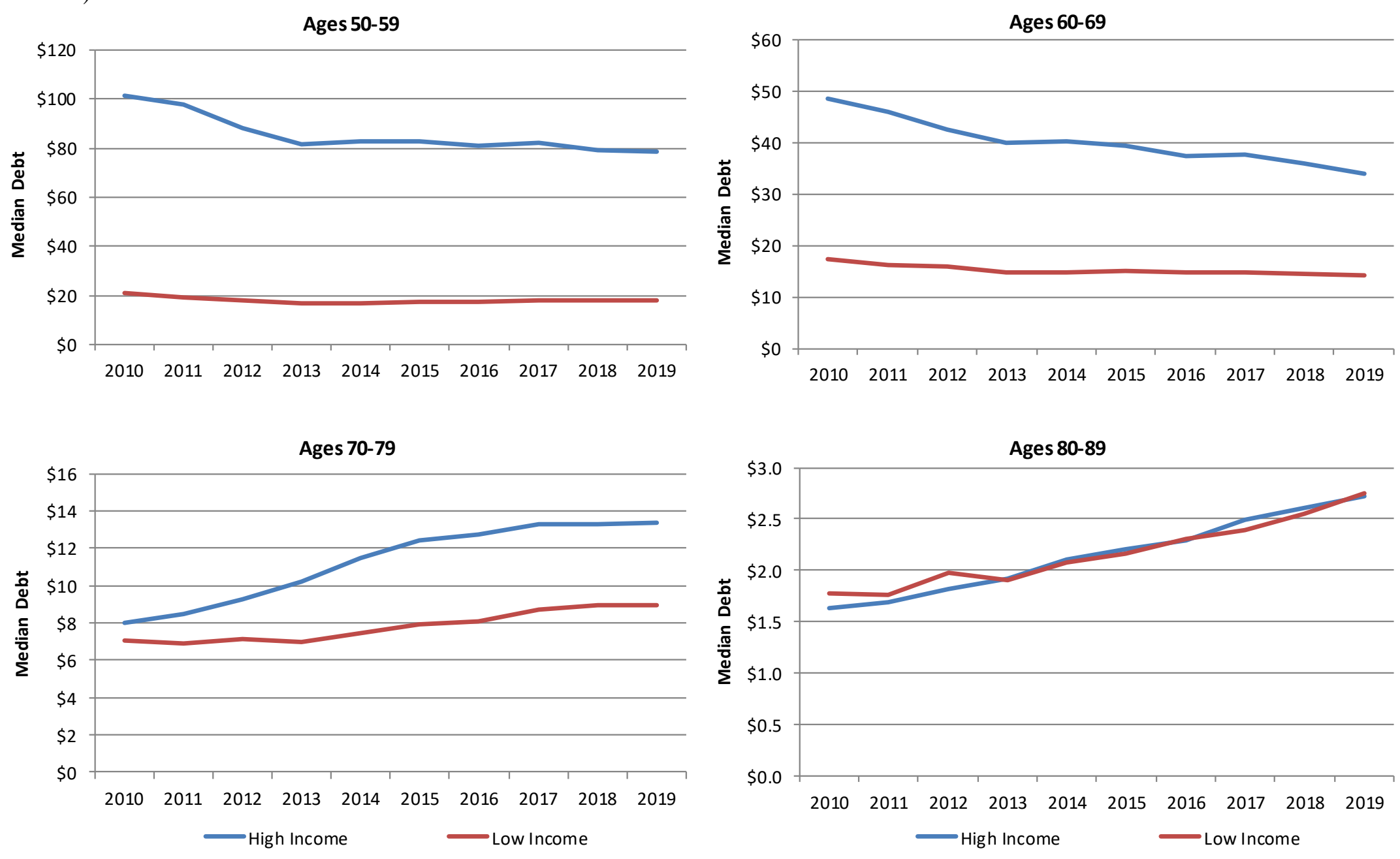
Figure 9. Median Non-mortgage Debt Among Adults Ages 50 to 89 With Debt, by Median Household Income within Zip Codes (Thousands of 2019 Dollars)

Ages 50-59

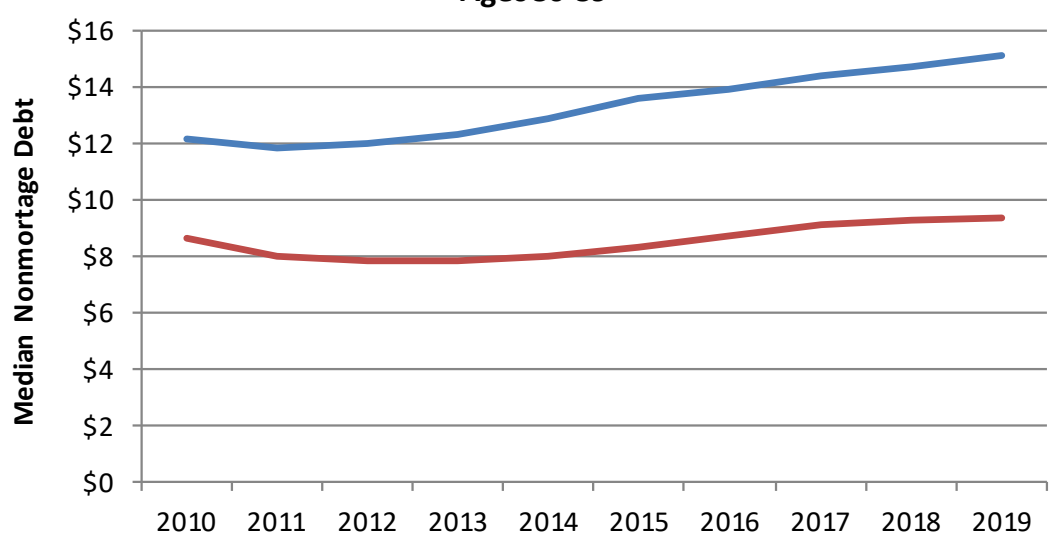

Ages 70-79

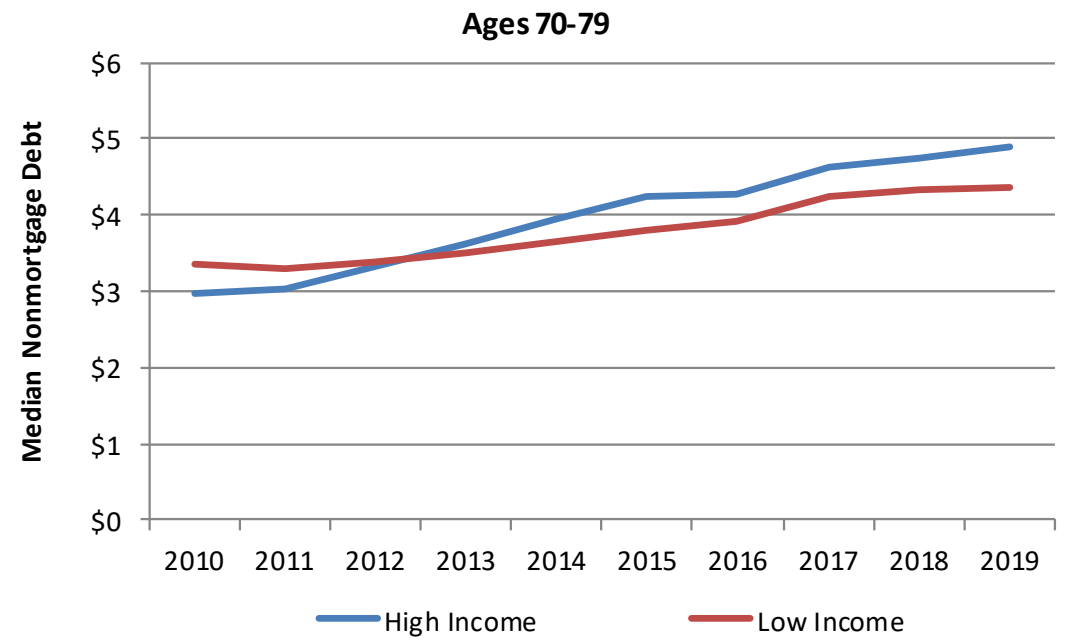

Ages 60-69

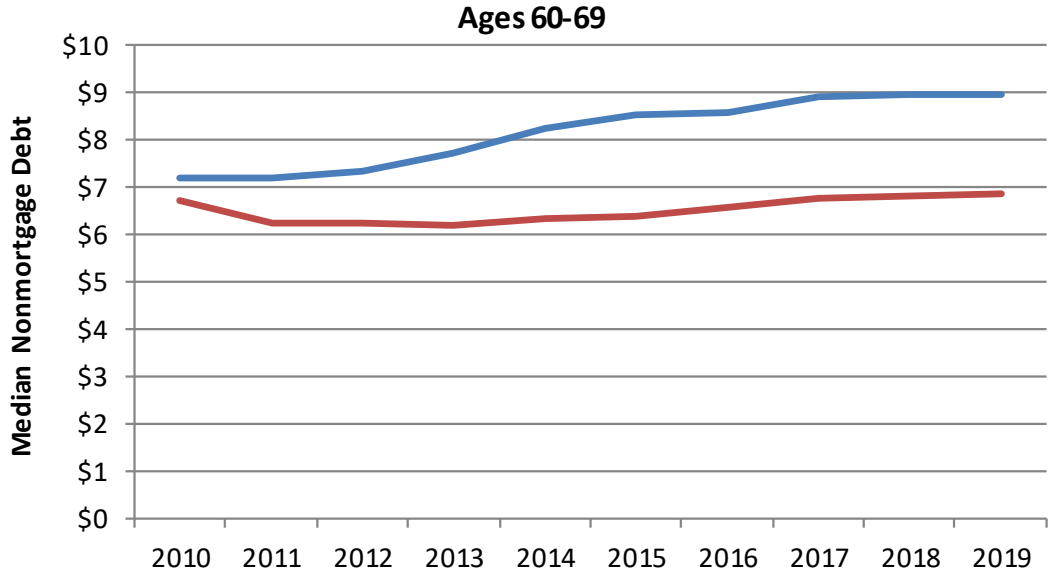

Ages 80-89

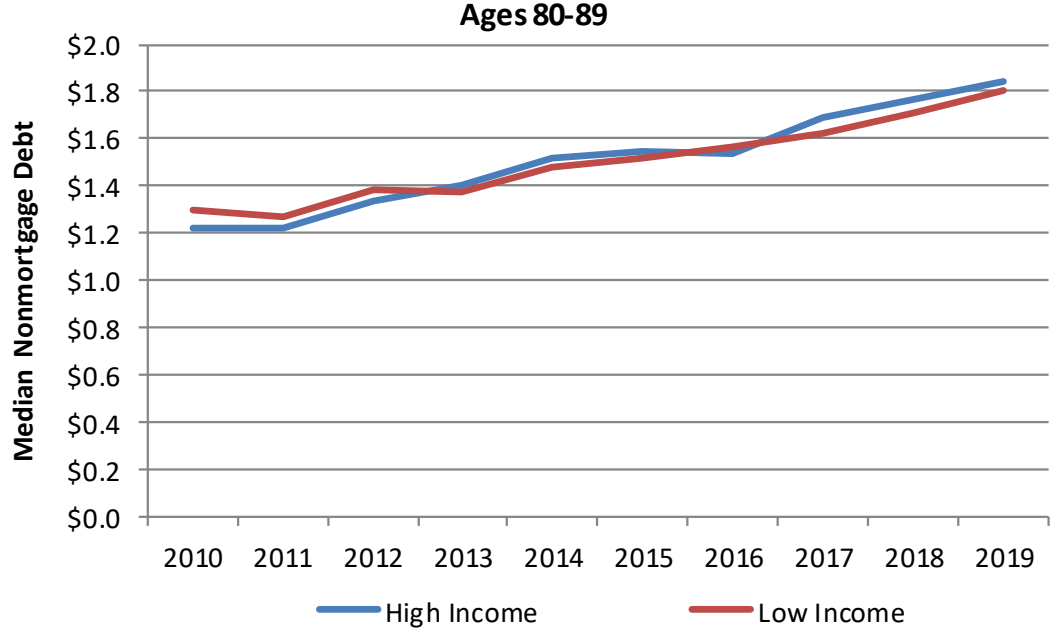


Figure 10. Mean Share of Total Debt from Sources Among Adults Ages 50 to 89 with Debt in 2019, by Median Household Income Within Zip Codes
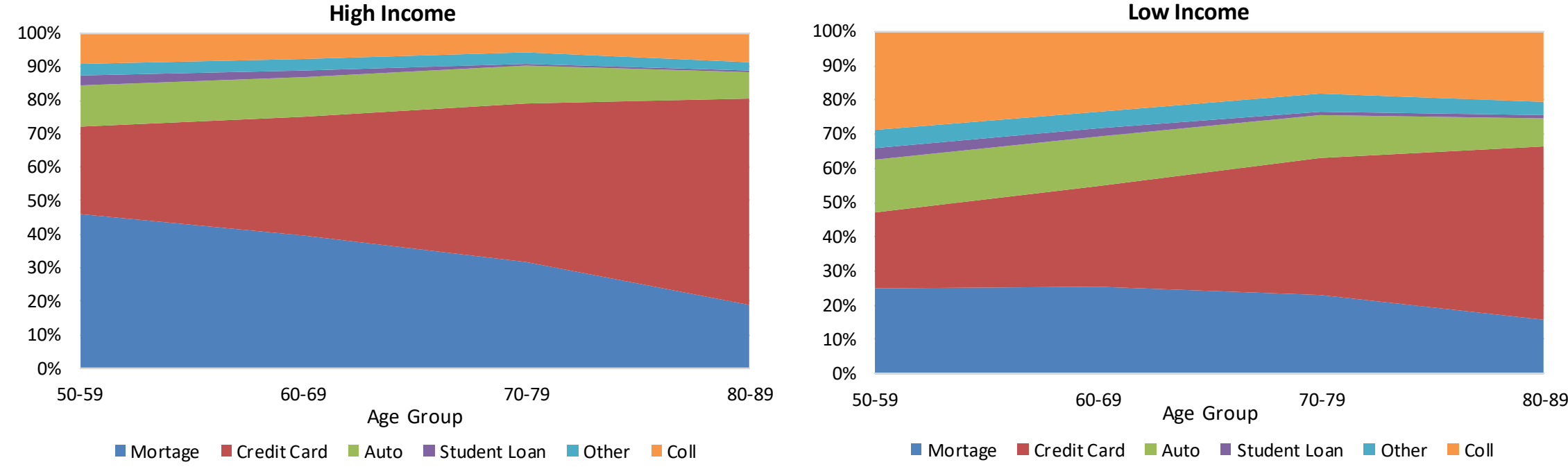
Figure 11. Median Debt Among Adults Ages 50 to 89 with Debt, by Percentage of White and Nonwhite Zip Code Residents (Thousands of 2019 Dollars)
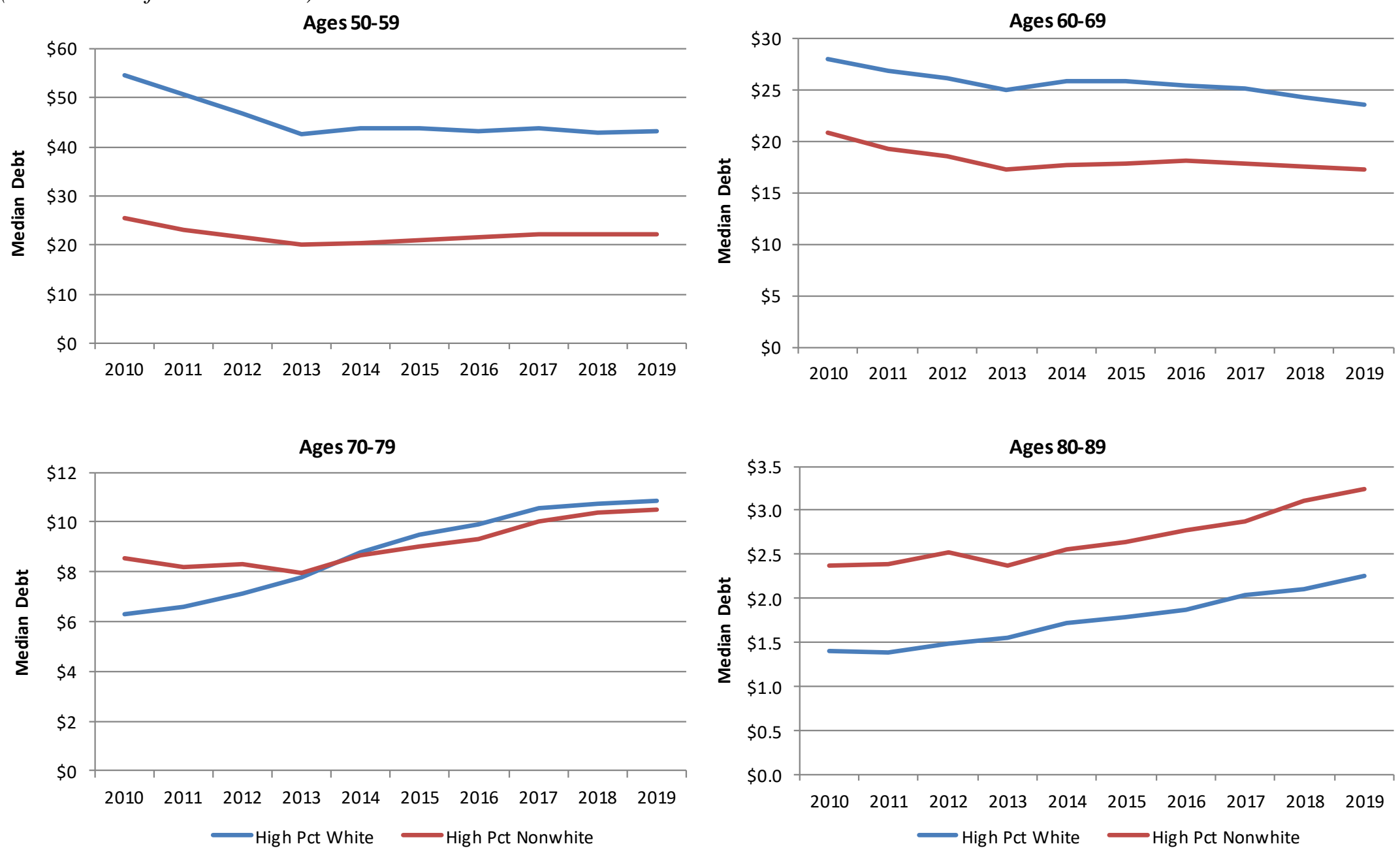
Figure 12. Median Non-mortgage Debt Among Adults Ages 50 to 89 with Debt, by Percentage of White and Nonwhite Zip Code Residents (Thousands of 2019 Dollars)
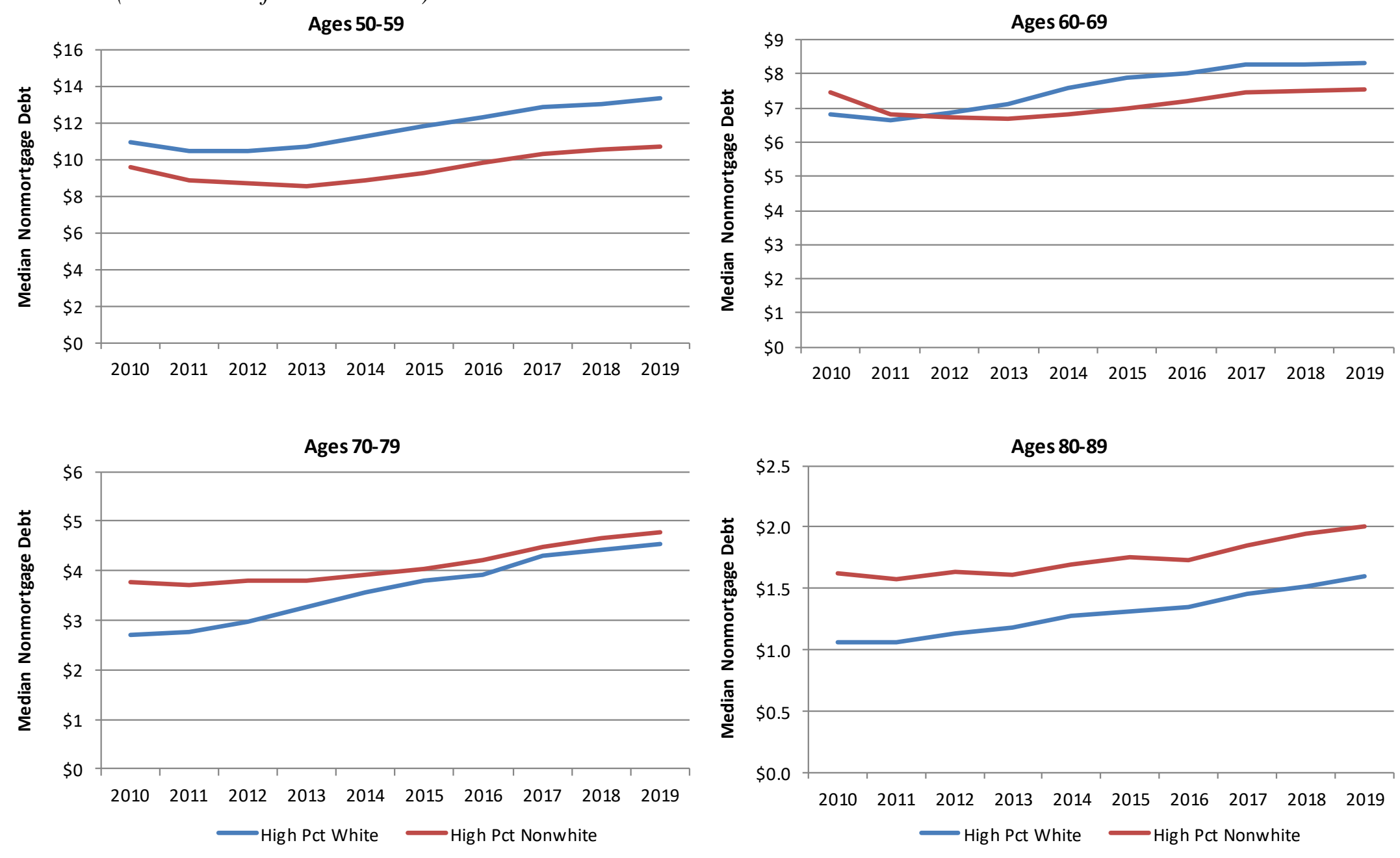
Figure 13. Mean Share of Total Debt from Sources Among Adults Ages 50 to 89 with Debt in 2019, by Percentage of White and Nonwhite Zip Code Residents
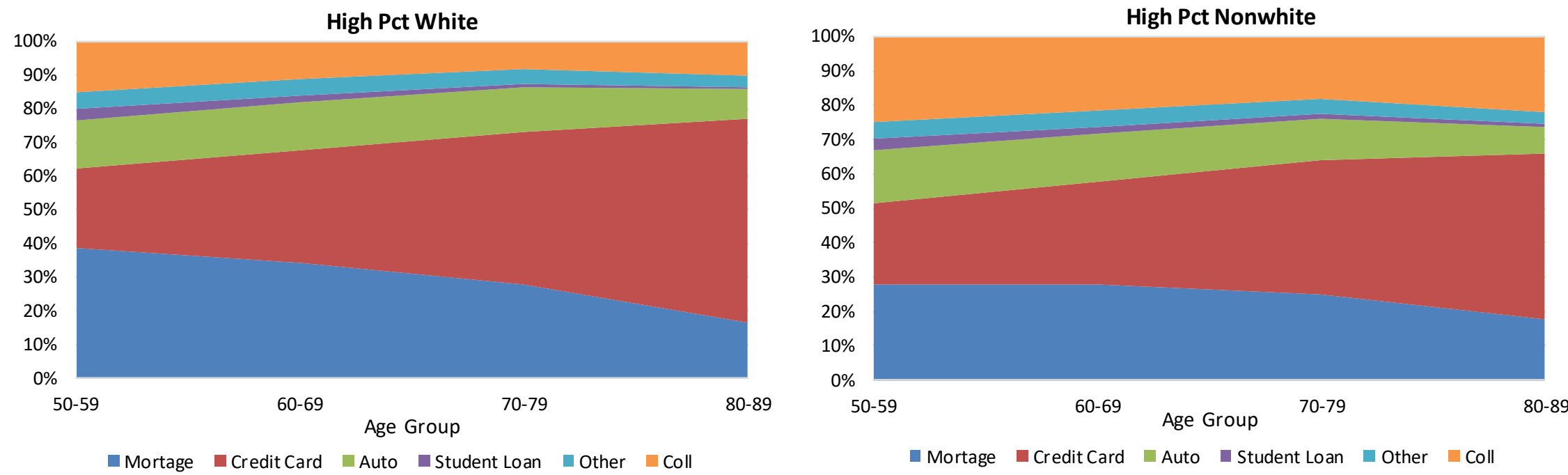
Figure 14a. Mean Credit Scores Among Adults Ages 50 to 89

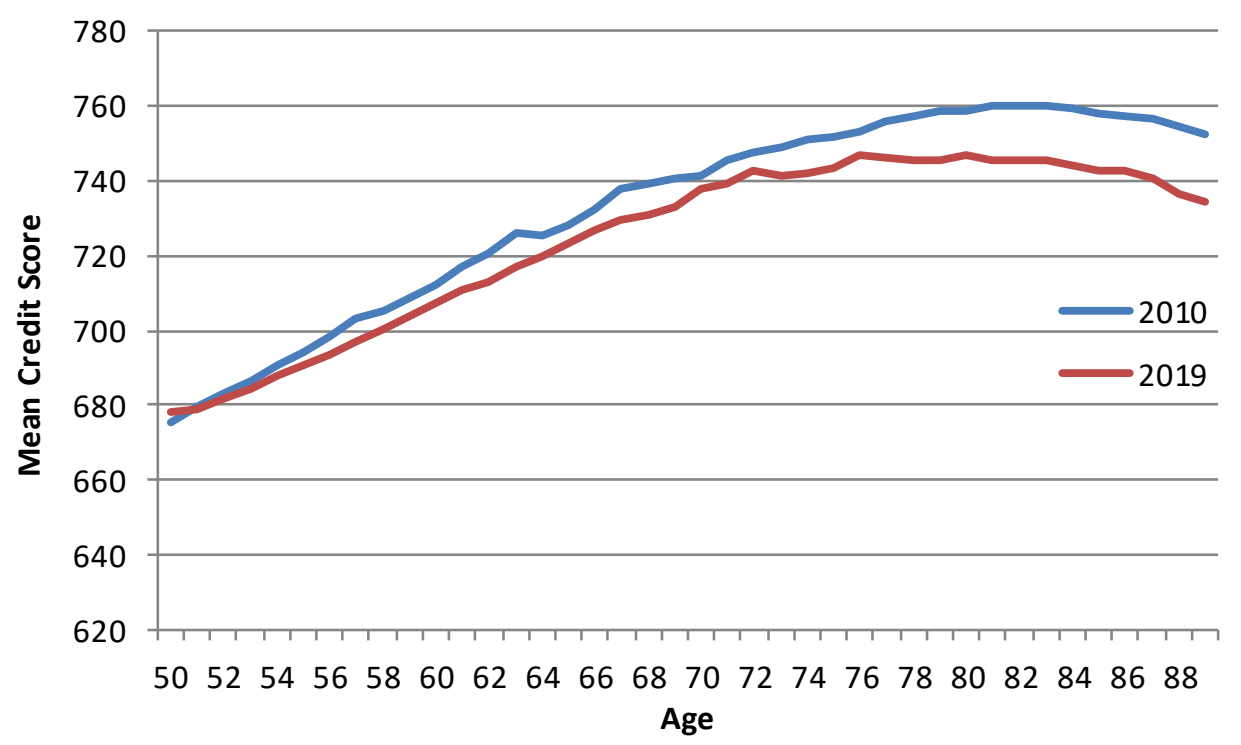

Figure 14b. Percentage of Adults Ages 50 to 89 with Subprime Credit Scores

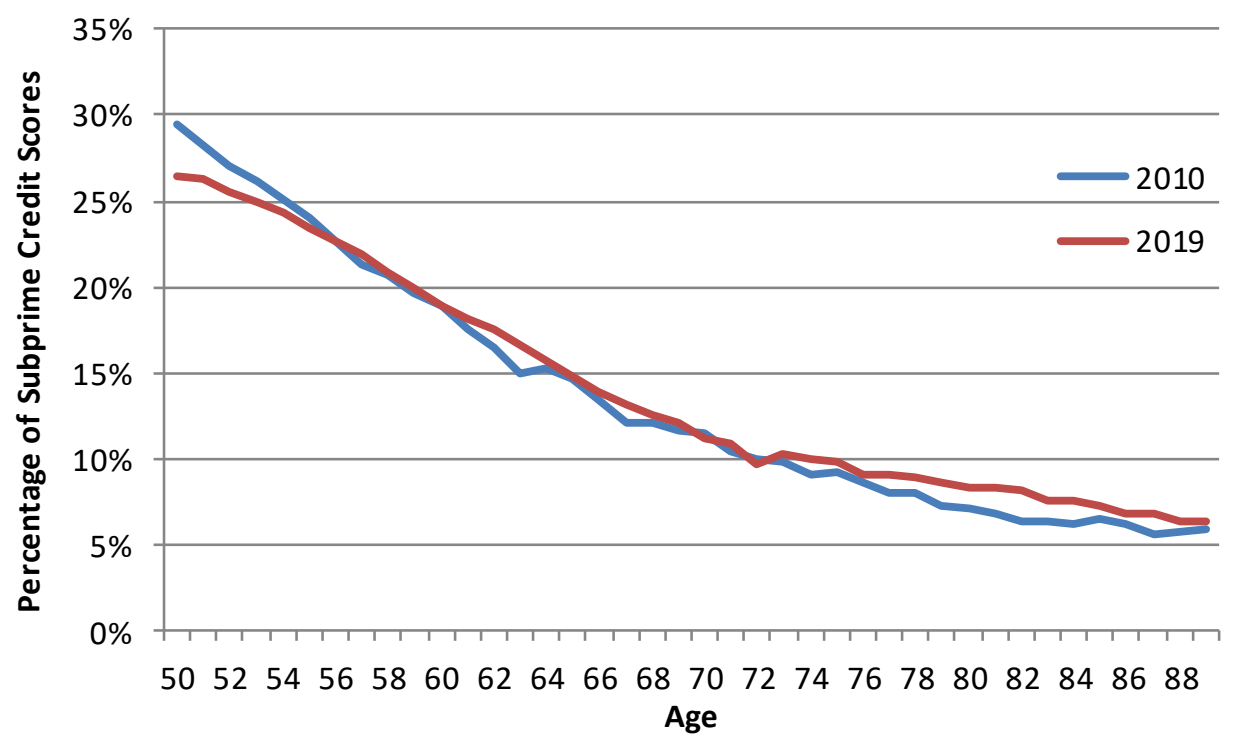


Figure 14c. Percentage of Adults Ages 50 to 89 with Super Prime Credit Scores

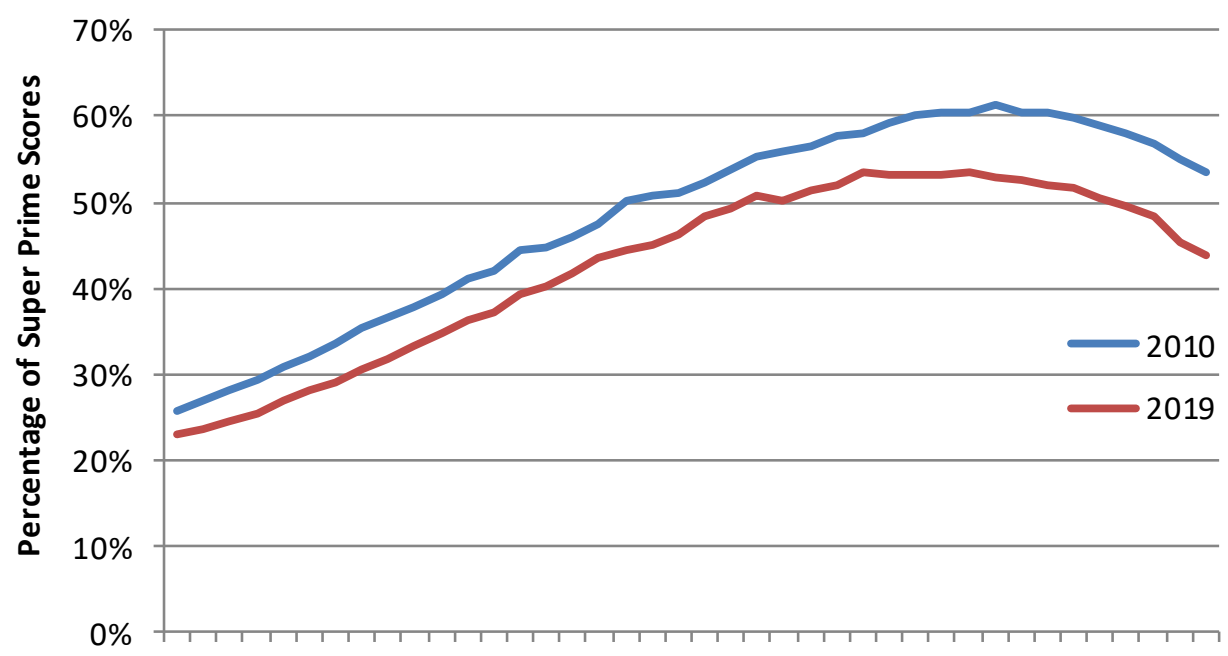

$\begin{array}{llllllllllllllllllll}50 & 52 & 54 & 56 & 58 & 60 & 62 & 64 & 66 & 68 & 70 & 72 & 74 & 76 & 78 & 80 & 82 & 84 & 86 & 88\end{array}$

Age

Figure 15. Distribution of Credit Scores Among Adults Ages 50 to 89

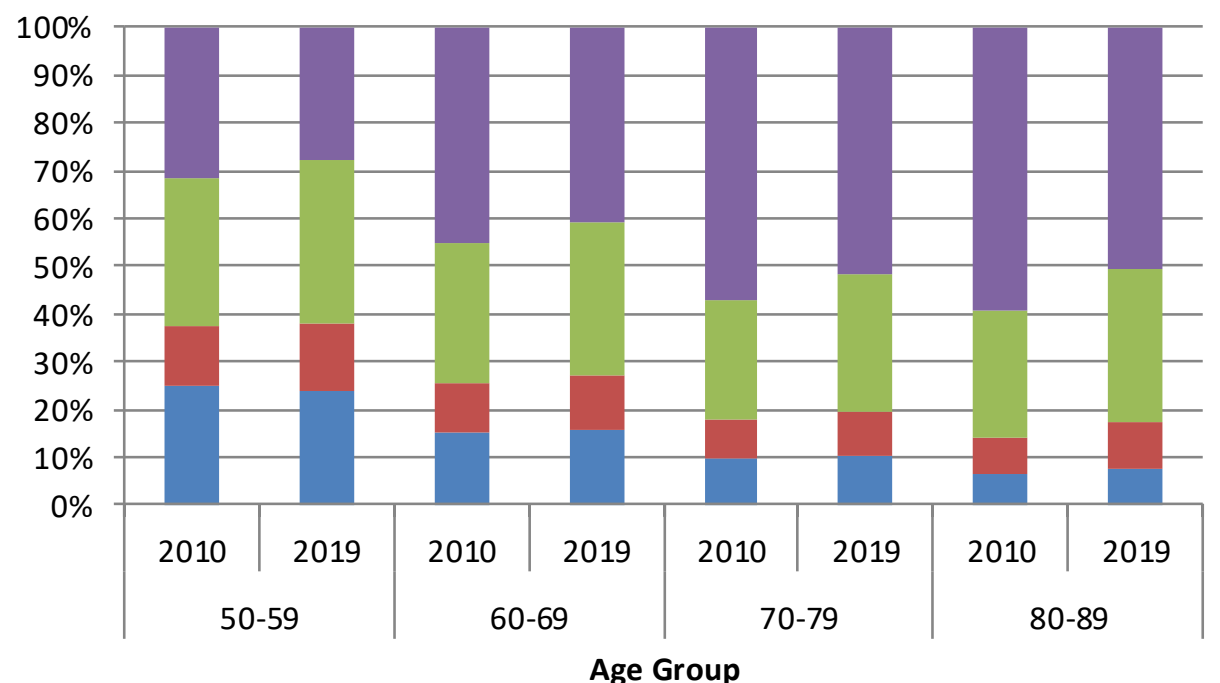

Subprime $\quad$ Near Prime $\quad$ Prime Super Prime 
Figure 16a. Financial Health of Adults Ages 50 to 89 Using Different Measures
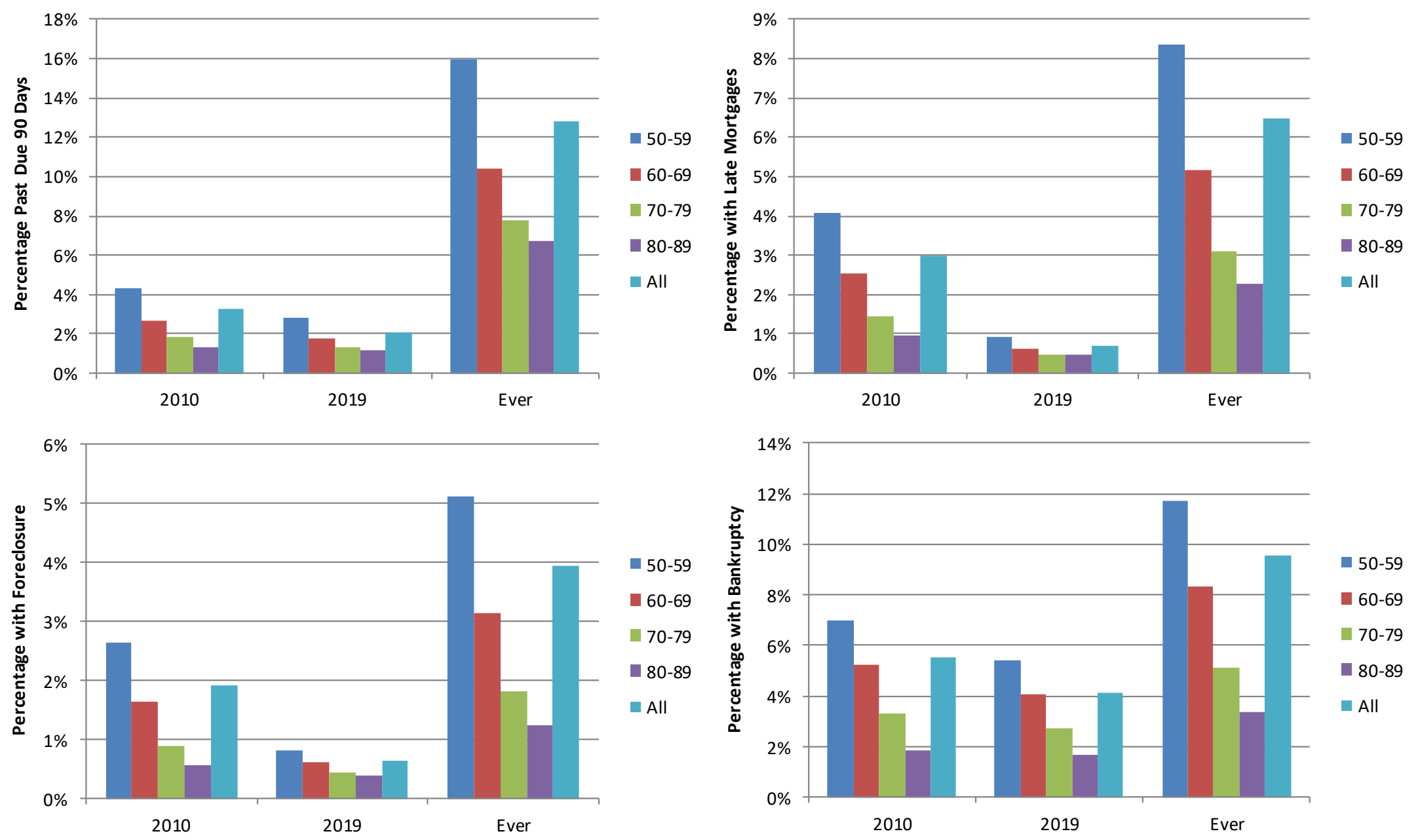
Figure 16b. Financial Health of Adults Ages 50 to 89 Using Different Measures

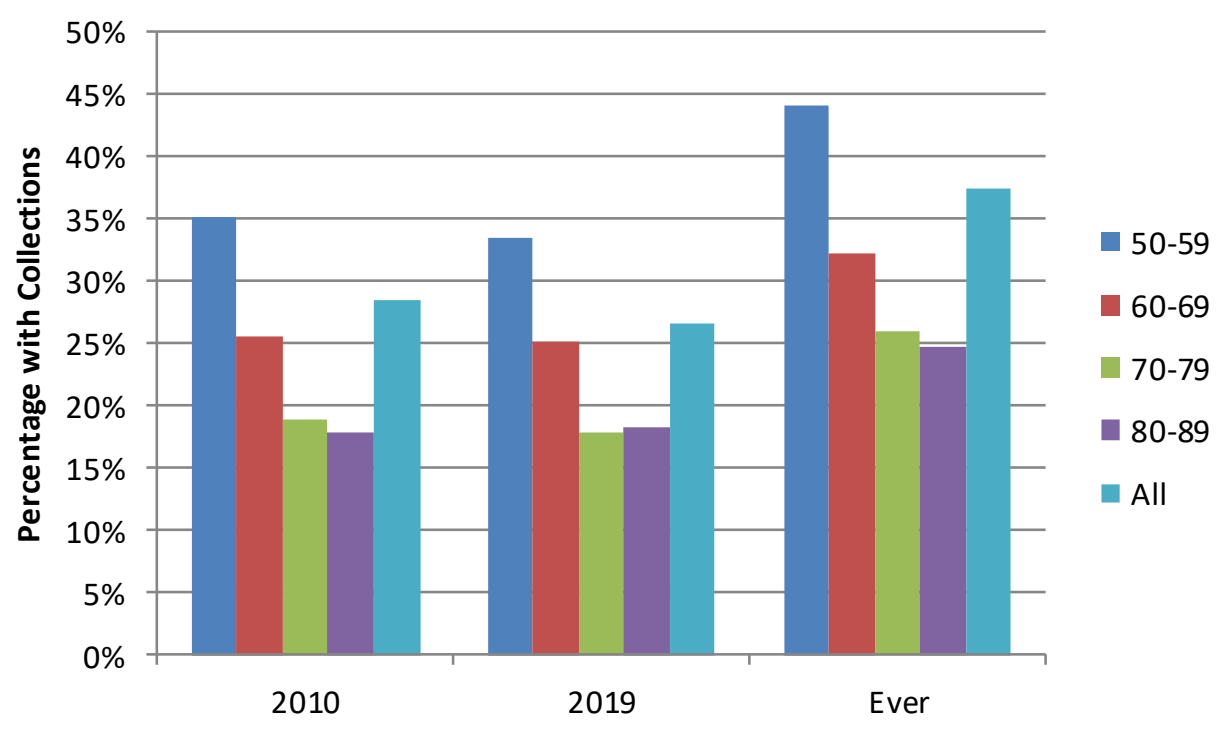

Figure 17a. Median Value of Debt Among Adults Ages 50 to 89 with Late Payments or in Collections

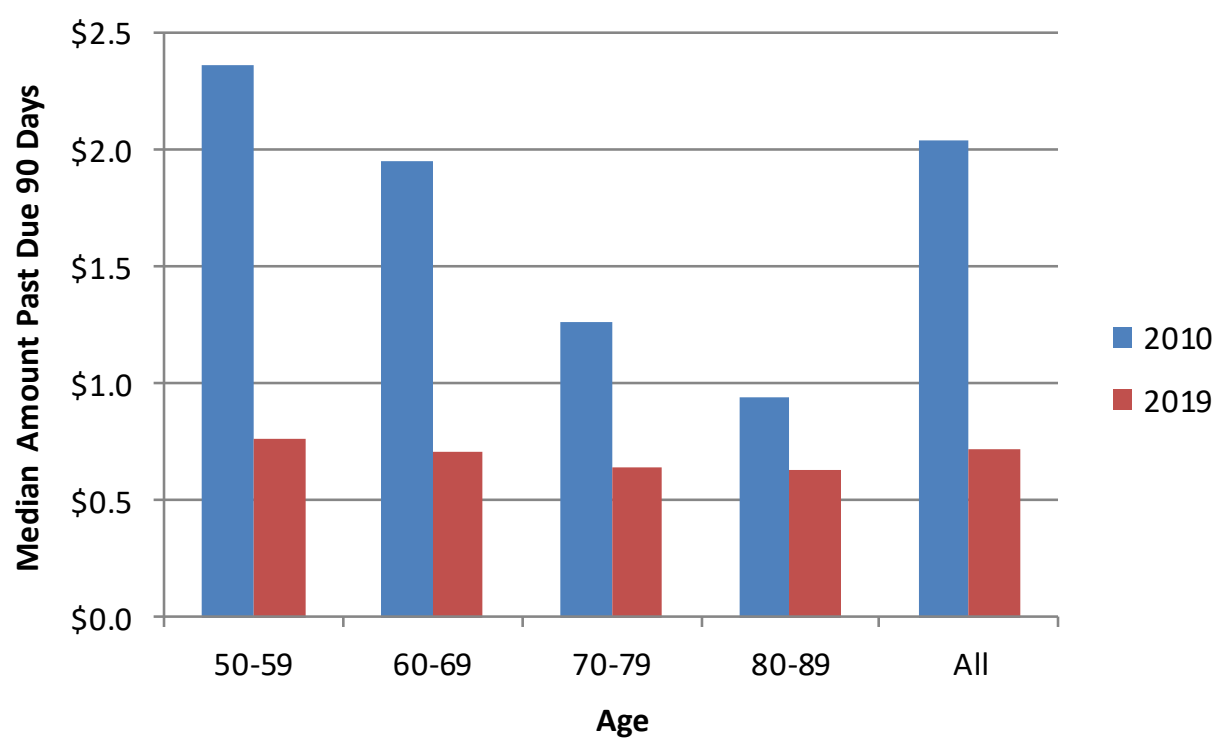


Figure 17b. Median Value of Debt Among Adults Ages 50 to 89 with Late Payments or in Collections

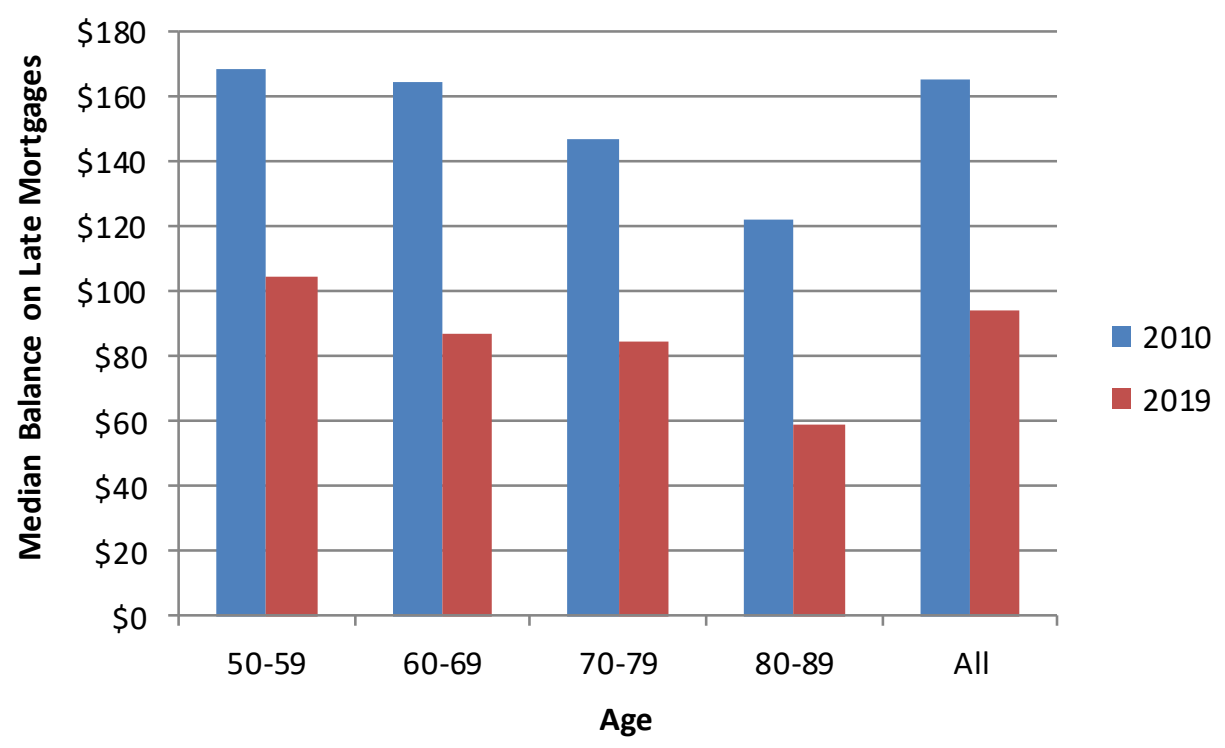

Figure 17c. Median Value of Debt Among Adults Ages 50 to 89 with Late Payments or in Collections

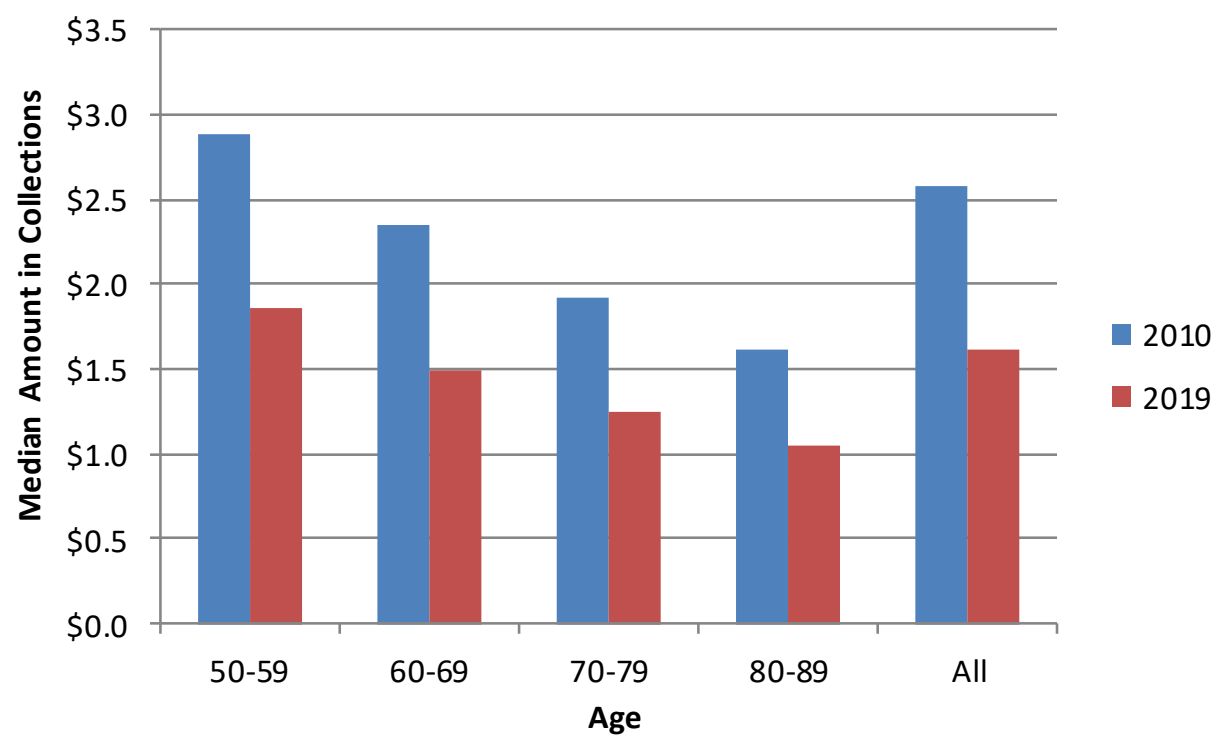


Figure 18. Distribution of Debt to Credit Limit Ratio (Credit Utilization) Among Adults Ages 50 to 89

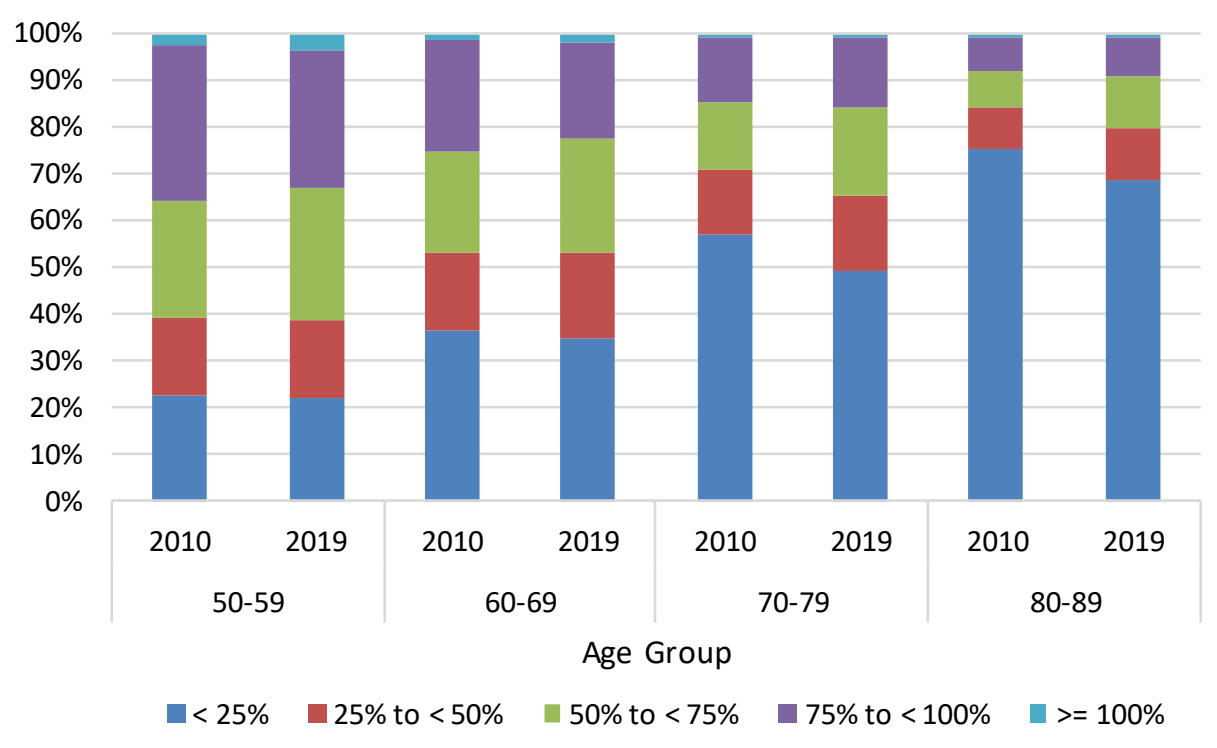




\section{Tables}

Table 1. Sources of Debt and Median Value of Debt Among Adults Ages 50 to 89

\begin{tabular}{|c|c|c|c|c|c|c|c|c|c|c|}
\hline & \multicolumn{2}{|c|}{$50-59$} & \multicolumn{2}{|c|}{$60-69$} & \multicolumn{2}{|c|}{ 70-79 } & \multicolumn{2}{|c|}{ 80-89 } & \multicolumn{2}{|c|}{ All } \\
\hline & 2010 & 2019 & 2010 & 2019 & 2010 & 2019 & 2010 & 2019 & 2010 & 2019 \\
\hline \multicolumn{11}{|l|}{ Percentage with Debt } \\
\hline Total Debt & $93.5 \%$ & $92.8 \%$ & $91.7 \%$ & $90.8 \%$ & $86.2 \%$ & $86.6 \%$ & $73.2 \%$ & $70.7 \%$ & $90.0 \%$ & $88.8 \%$ \\
\hline Debt Excl. Collections & $80.0 \%$ & $80.5 \%$ & $83.0 \%$ & $81.5 \%$ & $79.9 \%$ & $79.8 \%$ & $66.7 \%$ & $63.2 \%$ & $79.8 \%$ & $79.1 \%$ \\
\hline Non-Mortgage Debt & $91.8 \%$ & $91.5 \%$ & $89.8 \%$ & $89.2 \%$ & $84.5 \%$ & $84.9 \%$ & $71.7 \%$ & $68.9 \%$ & $88.3 \%$ & $87.2 \%$ \\
\hline Mortgage & $46.6 \%$ & $39.5 \%$ & $40.7 \%$ & $35.4 \%$ & $25.4 \%$ & $27.7 \%$ & $11.9 \%$ & $13.5 \%$ & $38.4 \%$ & $33.3 \%$ \\
\hline Credit Card & $67.5 \%$ & $70.2 \%$ & $73.3 \%$ & $72.8 \%$ & $72.7 \%$ & $72.9 \%$ & $61.4 \%$ & $58.0 \%$ & $69.6 \%$ & $70.4 \%$ \\
\hline Auto Loan & $30.5 \%$ & $38.4 \%$ & $25.8 \%$ & $31.8 \%$ & 16. $1 \%$ & $24.4 \%$ & $7.0 \%$ & $10.7 \%$ & $24.7 \%$ & $30.7 \%$ \\
\hline Student Loan & $6.8 \%$ & $8.2 \%$ & $3.2 \%$ & $5.0 \%$ & $1.1 \%$ & $1.9 \%$ & $0.7 \%$ & $1.0 \%$ & $4.3 \%$ & $5.2 \%$ \\
\hline Other & $18.9 \%$ & $19.4 \%$ & $16.3 \%$ & $16.4 \%$ & $11.5 \%$ & $12.3 \%$ & $6.3 \%$ & $5.8 \%$ & $15.8 \%$ & $15.7 \%$ \\
\hline Collections & $32.9 \%$ & $31.2 \%$ & $23.4 \%$ & $22.9 \%$ & $16.4 \%$ & $15.5 \%$ & $13.0 \%$ & $12.9 \%$ & $25.6 \%$ & $23.5 \%$ \\
\hline \multicolumn{11}{|c|}{ Median Value Among Those with Source (thousands of 2019 dollars) } \\
\hline Total Debt & $\$ 45.3$ & $\$ 34.7$ & $\$ 26.1$ & $\$ 21.7$ & $\$ 6.8$ & $\$ 10.8$ & $\$ 1.5$ & $\$ 2.4$ & $\$ 23.8$ & $\$ 20.2$ \\
\hline Debt Excl. Collections & $\$ 68.2$ & $\$ 49.9$ & $\$ 31.8$ & $\$ 27.3$ & $\$ 6.8$ & $\$ 12.6$ & $\$ 1.4$ & $\$ 2.6$ & $\$ 30.7$ & $\$ 25.7$ \\
\hline Non-Mortgage Debt & $\$ 10.6$ & $\$ 12.6$ & $\$ 7.0$ & $\$ 8.1$ & $\$ 2.9$ & $\$ 4.6$ & $\$ 1.1$ & $\$ 1.7$ & $\$ 6.8$ & $\$ 7.9$ \\
\hline Mortgage & $\$ 144.4$ & $\$ 146.9$ & $\$ 120.9$ & $\$ 117.7$ & $\$ 90.2$ & $\$ 104.1$ & $\$ 72.5$ & $\$ 79.8$ & $\$ 128.3$ & $\$ 126.2$ \\
\hline Credit Card & $\$ 3.8$ & $\$ 4.1$ & $\$ 2.7$ & $\$ 3.1$ & $\$ 1.6$ & $\$ 2.2$ & $\$ 0.8$ & $\$ 1.2$ & $\$ 2.6$ & $\$ 3.0$ \\
\hline Auto Loan & $\$ 14.5$ & $\$ 16.0$ & $\$ 14.0$ & $\$ 14.3$ & $\$ 12.3$ & $\$ 12.6$ & $\$ 10.9$ & $\$ 9.9$ & $\$ 14.0$ & $\$ 14.6$ \\
\hline Student Loan & $\$ 14.4$ & $\$ 19.5$ & $\$ 13.4$ & $\$ 16.1$ & $\$ 12.0$ & $\$ 13.8$ & $\$ 12.6$ & $\$ 12.7$ & $\$ 14.0$ & $\$ 17.8$ \\
\hline Other & $\$ 5.6$ & $\$ 6.5$ & $\$ 5.6$ & $\$ 5.9$ & $\$ 4.3$ & $\$ 5.3$ & $\$ 2.3$ & $\$ 3.8$ & $\$ 5.3$ & $\$ 6.0$ \\
\hline Collections & $\$ 2.9$ & $\$ 1.9$ & $\$ 2.4$ & $\$ 1.5$ & $\$ 1.9$ & $\$ 1.3$ & $\$ 1.6$ & $\$ 1.1$ & $\$ 2.6$ & $\$ 1.6$ \\
\hline
\end{tabular}


Table 2. Change in Debt and Sources of Debt Between 2010 and 2019 Among Adults Ages 50 to 89

\begin{tabular}{|c|c|c|c|c|c|c|c|c|}
\hline & \multirow[b]{2}{*}{$\begin{array}{c}\text { Share of } \\
\text { Adults }\end{array}$} & \multirow[b]{2}{*}{$\begin{array}{c}\text { Mean } \\
\text { Change }\end{array}$} & \multicolumn{6}{|c|}{ Share of Mean Change in Debt } \\
\hline & & & Mortgage & $\begin{array}{l}\text { Credit } \\
\text { Card }\end{array}$ & $\begin{array}{l}\text { Auto } \\
\text { Loan }\end{array}$ & $\begin{array}{c}\text { Student } \\
\text { Loan }\end{array}$ & Other & Collections \\
\hline \multicolumn{9}{|c|}{ Increase in Total Debt } \\
\hline $50-59$ & $32.2 \%$ & $\$ 66.1$ & $80 \%$ & $4 \%$ & $7 \%$ & $3 \%$ & $4 \%$ & $1 \%$ \\
\hline $60-69$ & $31.3 \%$ & $\$ 46.8$ & $81 \%$ & $4 \%$ & $8 \%$ & $1 \%$ & $4 \%$ & $1 \%$ \\
\hline $70-79$ & $28.0 \%$ & $\$ 23.8$ & $77 \%$ & $6 \%$ & $8 \%$ & $2 \%$ & $3 \%$ & $4 \%$ \\
\hline $80-89$ & $22.4 \%$ & $\$ 16.5$ & $77 \%$ & $6 \%$ & $7 \%$ & $2 \%$ & $2 \%$ & $7 \%$ \\
\hline All & $31.2 \%$ & $\$ 53.6$ & $80 \%$ & $4 \%$ & $8 \%$ & $3 \%$ & $4 \%$ & $1 \%$ \\
\hline \multicolumn{9}{|c|}{ Increase in Non-Mortgage Debt } \\
\hline $50-59$ & $43.9 \%$ & $\$ 18.1$ & $0 \%$ & $20 \%$ & $39 \%$ & $13 \%$ & $22 \%$ & $6 \%$ \\
\hline $60-69$ & $41.0 \%$ & $\$ 12.9$ & $0 \%$ & $23 \%$ & $41 \%$ & $6 \%$ & $23 \%$ & $7 \%$ \\
\hline $70-79$ & $33.1 \%$ & $\$ 7.7$ & $0 \%$ & $26 \%$ & $36 \%$ & $6 \%$ & $17 \%$ & $15 \%$ \\
\hline $80-89$ & $24.6 \%$ & $\$ 5.0$ & $0 \%$ & $27 \%$ & $28 \%$ & $6 \%$ & $11 \%$ & $27 \%$ \\
\hline All & $41.1 \%$ & $\$ 15.0$ & $0 \%$ & $21 \%$ & $39 \%$ & $11 \%$ & $22 \%$ & $7 \%$ \\
\hline \multicolumn{9}{|c|}{ Decrease in Total Debt } \\
\hline $50-59$ & $66.3 \%$ & $-\$ 99.2$ & $89 \%$ & $3 \%$ & $2 \%$ & $1 \%$ & $3 \%$ & $3 \%$ \\
\hline $60-69$ & $65.9 \%$ & $-\$ 84.2$ & $87 \%$ & $3 \%$ & $3 \%$ & $1 \%$ & $3 \%$ & $3 \%$ \\
\hline $70-79$ & $65.3 \%$ & $-\$ 48.3$ & $83 \%$ & $5 \%$ & $5 \%$ & $0 \%$ & $4 \%$ & $3 \%$ \\
\hline $80-89$ & $65.0 \%$ & $-\$ 30.4$ & $79 \%$ & $7 \%$ & $6 \%$ & $1 \%$ & $4 \%$ & $4 \%$ \\
\hline All & $66.0 \%$ & $-\$ 86.0$ & $88 \%$ & $3 \%$ & $2 \%$ & $1 \%$ & $3 \%$ & $3 \%$ \\
\hline \multicolumn{9}{|c|}{ Decrease in Non-Mortgage Debt } \\
\hline $50-59$ & $53.9 \%$ & $-\$ 20.8$ & $0 \%$ & $22 \%$ & $25 \%$ & $9 \%$ & $22 \%$ & $23 \%$ \\
\hline $60-69$ & $55.4 \%$ & $-\$ 17.4$ & $0 \%$ & $25 \%$ & $27 \%$ & $5 \%$ & $25 \%$ & $18 \%$ \\
\hline $70-79$ & $59.1 \%$ & $-\$ 10.9$ & $0 \%$ & $30 \%$ & $28 \%$ & $2 \%$ & $24 \%$ & $16 \%$ \\
\hline $80-89$ & $61.6 \%$ & $-\$ 7.4$ & $0 \%$ & $34 \%$ & $26 \%$ & $3 \%$ & $19 \%$ & $18 \%$ \\
\hline All & $55.2 \%$ & $-\$ 17.9$ & $0 \%$ & $24 \%$ & $26 \%$ & $7 \%$ & $23 \%$ & $20 \%$ \\
\hline
\end{tabular}


Table 3. Distribution of Spells and Duration of Poor Credit Among Adult Ages 50 to 89

\begin{tabular}{|c|c|c|c|c|c|c|c|c|c|}
\hline & \multirow[b]{3}{*}{ All } & \multirow{2}{*}{\multicolumn{4}{|c|}{ Age Group }} & \multicolumn{4}{|c|}{ Zip Code Characteristics } \\
\hline & & & & & & \multicolumn{2}{|c|}{$\begin{array}{c}\text { Median Household } \\
\text { Income } \\
\end{array}$} & \multicolumn{2}{|c|}{$\begin{array}{c}\text { Share of } \\
\text { Nonwhite } \\
\text { Residents } \\
\end{array}$} \\
\hline & & $50-59$ & 60-69 & 70-79 & 80-89 & High & Low & Low & High \\
\hline \multicolumn{10}{|c|}{ Spells of Poor Credit } \\
\hline 0 & 79.7 & 77.2 & 82.1 & 81.5 & 77.7 & 83.5 & 73.3 & 81.4 & 71.7 \\
\hline 1 & 14.4 & 15.9 & 12.8 & 13.8 & 17.2 & 11.9 & 18.7 & 13.3 & 19.9 \\
\hline 2 & 5.0 & 5.9 & 4.3 & 4.1 & $5.2^{*}$ & 4.0 & 6.8 & 4.5 & 7.2 \\
\hline $3+$ & 0.9 & 1.1 & 0.7 & 0.6 & - & 0.7 & 1.2 & 0.8 & 1.3 \\
\hline Mean & 1.33 & 1.36 & 1.33 & 1.29 & 1.25 & 1.33 & 1.35 & 1.33 & 1.35 \\
\hline \multicolumn{10}{|c|}{$\begin{array}{l}\text { Duration of Spells Among Those with } \\
\text { Spells }\end{array}$} \\
\hline 1 & 49.2 & 48.3 & 49.4 & 51.2 & 54.6 & 51.7 & 46.7 & 50.0 & 46.8 \\
\hline 2 & 19.6 & 19.2 & 20.0 & 20.3 & 20.5 & 19.4 & 19.6 & 19.6 & 19.8 \\
\hline 3 & 9.8 & 10.1 & 9.9 & 9.0 & 7.4 & 9.5 & 10.1 & 9.8 & 10.1 \\
\hline 4 & 6.1 & 6.3 & 6.1 & 5.6 & 4.3 & 5.9 & 6.6 & 6.0 & 6.4 \\
\hline $5+$ & 15.3 & 16.0 & 14.7 & 13.8 & 13.3 & 13.5 & 17.1 & 14.6 & 16.9 \\
\hline Mean & 2.4 & 2.5 & 2.4 & 2.3 & 2.2 & 2.3 & 2.6 & 2.4 & 2.6 \\
\hline
\end{tabular}

Note: * Represents 2 or more spells of poor credit. 
Table 4. Regression Coefficients of the Relationship Between the Value of Debt and the Likelihood of Entering and Exiting Poor Credit Spell

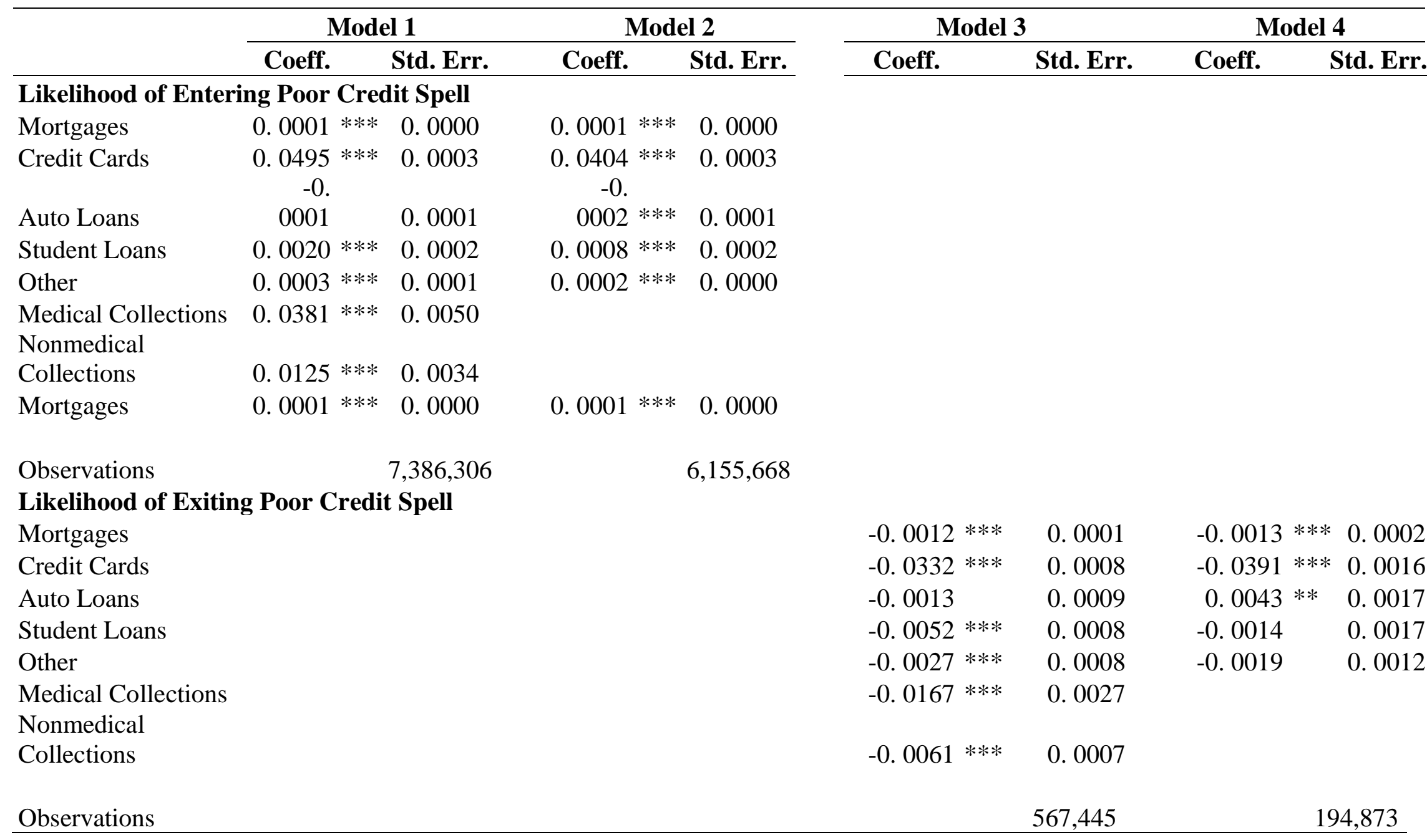

Note: Debt values are measured in \$10,000. Model 2 and Model 4 exclude those who ever had debt in collections. All models also include age, year, state dummies, and zip code characteristics. 


\section{RECENT WORKING PAPERS FROM THE CENTER FOR RETIREMENT RESEARCH AT BOSTON COLLEGE}

Do People Work Longer When They Live Longer?

Damir Cosic, Aaron R. Williams, and C. Eugene Steuerle, December 2020

Do State and Local Government Employees Save Outside of Their Defined Benefit Plans When They Need To?

Laura D. Quinby and Geoffrey T. Sanzenbacher, November 2020

How Much Taxes Will Retirees Owe on Their Retirement Income?

Anqi Chen and Alicia H. Munnell, November 2020

A Behavioral Economics Assessment of SSDI Earnings Reporting Documents

Denise Hoffman, Jonah Deutsch, and Britta Seifert, November 2020

How Accurate Are Retirees' Assessments of Their Retirement Risk?

Wenliang Hou, July 2020

Is Nontraditional Work at Older Ages Associated with Better Retirement Security?

Matthew S. Rutledge and Gal Wettstein, July 2020

New Insights on Self-Employment of Older Adults in the United States

Joelle Abramowitz, July 2020

What Jobs Do Employers Want Older Workers to Do?

Alicia H. Munnell, Gal Wettstein, and Abigail N. Walters, June 2020

Technological Innovation and Labor Income Risk

Leonid Kogan, Dimitris Papanikolaou, Lawrence D. W. Schmidt, and Jae Song, June 2020

Are Older Nontraditional Workers Able to Find Health and Retirement Coverage?

Matthew S. Rutledge, March 2020

Employer Perceptions of Older Workers - Surveys from 2019 and 2006

Alicia H. Munnell and Gal Wettstein, March 2020

Are Homeownership Patterns Stable Enough to Tap Home Equity?

Alicia H. Munnell, Abigail N. Walters, Anek Belbase, and Wenliang Hou, January 2020

The Impact of the Minimum Wage on DI Participation

Gary V. Engelhardt, January 2020

All working papers are available on the Center for Retirement Research website (https://crr.bc.edu) and can be requested by e-mail (crr@bc.edu) or phone (617-552-1762). 